\title{
La fiscalización de las políticas sociales: funcionamiento e impacto de las deducciones fiscales reembolsables
}

\author{
Joseba Zalakain \\ SIIS Centro de Documentación y Estudios, Fundación Eguía-Careaga \\ jzalakain@siis.net
}

\begin{abstract}
Mendebaldeko hainbat herrialdetako gizartepolitikek fiskalizazio-prozesu batera bidea hartu zuten azken urteotan, eta, horren ondorioz, lehen Gizarte Segurantzak kudeatzen zituen prestazio ekonomikoen zati bat edo prestazio zuzenaren bidezko gizarte-laguntzako sistemak orain kenkari edo desgrabazio fiskalen bidez bideratzen dira. Berariaz, diru-sarrerak bermatzeko eta familia-sostengurako politika-arloan, ez da beherakadarik ezagutu mota horretako lanabes fiskalen protagonismoan. Artikulu honen xedea Europan, Amerikan eta Ozeanian dauden kreditusistemen eta zerga-kenkari berreskuragarrien funtzionamendua deskribatzea da, baita pobreziamurrizketan, lan-txertaketan, zergen izaera progresiboan edo biztanleriaren ongizatearen hobekuntzan dituzten ondorioak identifikatzea ere; eta Estatu espainiarrean gizarte-babeseko sistema eguneratzeko zenbait ondorio lortzea, eta are gehiago, Euskal Autonomia Erkidegoan.
\end{abstract}

\section{GAKO-HITZAK:}

Estatu soziala, pobrezia, prestazio ekonomikoak, zergak, eraginak, esperientziak, nazioarteko panorama.
Las políticas sociales de numerosos países occidentales asisten en los últimos años a un proceso de fiscalización, de forma que una parte de las prestaciones económicas que anteriormente gestionaban la Seguridad Social o los sistemas de asistencia social en forma de prestación directa se canalizan ahora mediante deducciones o desgravaciones fiscales. Especialmente en el ámbito de las políticas de garantía de ingresos y de apoyo a las familias, el protagonismo de este tipo de herramientas fiscales no ha dejado de crecer. Este artículo persigue describir el funcionamiento de los sistemas de créditos o deducciones fiscales reembolsables existentes en Europa, América y Oceanía, e identificar sus efectos en términos de reducción de la pobreza, inclusión laboral, progresividad fiscal o mejora del bienestar de la población, así como extraer algunas conclusiones de cara a la actualización de los sistemas de protección social en el Estado español y, más concretamente, en la Comunidad Autónoma del País Vasco.

\section{Palabras Clave:}

Estado social, pobreza, prestaciones económicas, impuestos, efectos, experiencias, panorama internacional. 


\section{Introducción y metodología}

\subsection{Objetivos}

Como señalan Ferrarini, Nelson y Höög (2012: 137), "los Estados del Bienestar están siendo objeto de una sutil y en ocasiones inadvertida transformación: la fiscalización de las prestaciones sociales. Este cambio es especialmente notable en el ámbito de las políticas familiares, donde en los últimos años se han introducido una serie de créditos o deducciones fiscales infantiles que han modificado tanto el nivel como la composición de las políticas familiares". En efecto, las políticas sociales de buena parte de los países occidentales asisten en los últimos años a un proceso de fiscalización, de tal forma que una parte de las prestaciones económicas que anteriormente se gestionaban desde la Seguridad Social o desde los sistemas de asistencia social en forma de prestación directa se canalizan ahora mediante deducciones 0 desgravaciones fiscales (McCabe, 2018; Ferrarini, Nelson y Höög, 2012; Avram, 2018).

De hecho, puede decirse que el recurso a las herramientas fiscales -exenciones, desgravaciones y deducciones, en general vinculadas al Impuesto sobre la Renta de las Personas Físicas (IRPF) - es una de las tendencias que está modificando las formas de provisión de las ayudas a las familias en el marco de una creciente integración de las políticas sociales y fiscales ${ }^{1}$. Como explican Hermida y Noguera (2013: 108), “durante la última década y media es posible identificar una tendencia de reforma de los sistemas fiscales y de protección social en varios países de la Unión Europea, que persigue una mayor integración y coherencia entre los impuestos personales y las prestaciones sociales en dinero. Dichas reformas se inspiran parcialmente en los créditos fiscales que ya desde la década de 1970 se introdujeron en los Estados Unidos (y posteriormente en otros países anglosajones como Australia, Canadá o Nueva Zelanda)".

Especialmente en el ámbito de las políticas de garantía de ingresos y de apoyo a las familias, el protagonismo de este tipo de herramientas fiscales no ha dejado de crecer en los últimos años, tal y como ponen de manifiesto Ferrarini, Nelson y Höög (2012) en el caso específico de las políticas de apoyo a las familias con hijos/as. De acuerdo a estos autores, si en 1960 este tipo de herramientas se usaban en un solo país (Dinamarca), en 2005 se utilizan en trece. De hecho, es la expansión de este tipo de deducciones a partir sobre todo de mediados de los años noventa lo que explica el incremento en la cobertura de las prestaciones familiares que, en su ausencia, habrían ido reduciendo su capacidad de protección.

${ }^{1}$ Las políticas de integración de impuestos y prestaciones son aquellas que buscan o mantienen la consistencia en el continuo impuestos-prestaciones, estableciendo un "tramo negativo" de impuesto (esto es, permitiendo que la deducción o desgravación fiscal pueda convertirse en prestación directa) y, a la inversa, posibilitando que se pueda cobrar una prestación como deducción o desgravación fiscal si se tiene renta imponible (Hermida y Noguera, 2013).
Las razones para esa "fiscalización" son varias. Para McCabe (2018), una de ellas tiene que ver con las políticas de austeridad introducidas desde hace ya décadas. En ese contexto, las deducciones fiscales -que se computan a efectos políticos y macroeconómicos como pérdidas de recaudación y no como gasto público- tienen una aceptación mucho mayor que las prestaciones directas. El hecho de que hayan sido fundamentalmente dirigidas a prevenir la pobreza infantil y la pobreza en el empleo -dos formas "decentes" de pobreza- explica también gran parte de su éxito. En cualquier caso, la principal razón de su creciente aceptación - al menos en algunos países- hay que buscarla en su consideración como herramienta para la reducción de la presión fiscal a la que están sometidas las clases medias y no, en primera instancia al menos, como herramienta de redistribución para los grupos de menor renta.

Efectivamente, como se explica más adelante, dentro de este proceso de fiscalización coexisten dos tipos de enfoques diferentes que parten de lógicas en cierto modo contrapuestas. Las deducciones tradicionales - no reembolsables- se limitan a reducir la deuda tributaria de los contribuyentes y se basan por tanto en una lógica de reducción de la presión fiscal para los contribuyentes de ingresos medios o bajos. Por definición, no benefician -o lo hacen en muy escasa medida- a los contribuyentes de muy bajos ingresos, con responsabilidades tributarias demasiado pequeñas para beneficiarse de una rebaja de impuestos, o a quienes carecen de ingresos. Por el contrario, las deducciones reembolsables benefician a todas las personas potencialmente beneficiarias ya que si el montante de la deducción es superior la deuda tributaria, la diferencia se abona a las personas contribuyentes como una prestación neta. Como también se señala más adelante, estas herramientas plantean algunas ventajas -normalización, simplificación, menor estigmatización, etc.-, pero también algunas desventajas que es necesario subrayar.

Este artículo tiene por objetivo describir el funcionamiento de los sistemas de créditos o deducciones fiscales reembolsables existentes en Europa, América y Oceanía, e identificar sus efectos en términos de reducción de la pobreza, inclusión laboral o mejora del bienestar de la población, así como extraer algunas conclusiones de cara a la actualización de los sistemas de protección social en el Estado español y, más concretamente, en la Comunidad Autónoma del País Vasco.

En lo que se refiere a los modelos analizados, se describen los existentes en Reino Unido, Francia, Eslovaquia, Austria, España, Alemania, Italia, Bélgica, Estados Unidos, Canadá, República Checa y Nueva Zelanda. Se han dejado fuera del análisis numerosos sistemas de deducciones y desgravaciones existentes en otros países debido a su carácter no reembolsable. Desde ese punto de vista, si bien es cierto que existen experiencias de gran interés en países como Dinamarca, Irlanda, Japón, Corea, Países Bajos, 
Portugal o Suecia, esos modelos no se han analizado debido a que no se trata de créditos reembolsables.

\subsection{Metodología y estructura del artículo}

Desde el punto de vista metodológico, esta revisión amplía y actualiza un reciente informe realizado para el Observatorio de la Realidad Social del Departamento de Derechos Sociales del Gobierno de Navarra, que a su vez se basaba en un informe anterior realizado en 2013 para la Diputación Foral de Gipuzkoa, incorporando información más actualizada sobre los diferentes sistemas y los resultados de las evaluaciones realizadas a lo largo de los últimos años. La documentación analizada ha sido seleccionada, fundamentalmente, de la base de datos bibliográfica sobre políticas sociales que gestiona el SIIS Centro de Documentación y Estudios de la Fundación Eguía Careaga.

La estructura del informe es la siguiente:

- Tras este primer apartado introductorio, el segundo apartado explica el marco general de las deducciones a partir del renovado interés existente en relación con lo que se ha venido en llamar Estado de Bienestar oculto y con el papel de las deducciones fiscales reembolsables en la reestructuración de las políticas sociales.

- El tercer apartado explica con cierto detalle el funcionamiento de una treintena de deducciones fiscales reembolsables desarrolladas en doce países de la Organización para la Cooperación y el Desarrollo Económicos (OCDE).

- El cuarto apartado revisa las principales conclusiones sobre el impacto de las deducciones fiscales reembolsables en lo que se refiere a la reducción de la pobreza, la inserción laboral, la mejora del bienestar infantil, la progresividad del sistema fiscal o la reducción de los errores administrativos en la gestión del sistema.

- El quinto y último apartado resume las ventajas y desventajas de estas herramientas, así como su posible utilidad de cara a la mejora de las políticas de garantía de ingresos y apoyo a las familias en el Estado español y, particularmente, en la Comunidad Autónoma del País Vasco.

\section{Deducciones fiscales reembolsables: panorama general}

\subsection{El papel de las deducciones reembolsables en el ámbito de las políticas sociales}

\subsubsection{El Estado de Bienestar oculto y la fiscalización de las políticas sociales}

Al margen de su función recaudatoria, la fiscalidad constituye un elemento esencial en el diseño de las políticas sociales, en la medida en que el diseño de los diferentes impuestos incluye medidas orientadas a incentivar determinadas conductas y a compensar determinadas situaciones, así como a garantizar un nivel suficiente de progresividad en la imposición de las cargas tributarias. En el caso del impuesto sobre la renta de las personas físicas, eje esencial de la mayor parte de los sistemas tributarios, se busca mediante bonificaciones, desgravaciones o deducciones alterar el comportamiento de los contribuyentes a través de variados estímulos en relación, por ejemplo, con el ahorro para la jubilación, la adquisición de vivienda habitual o el gasto privado en educación. Además, el impuesto sobre la renta tiene en cuenta las diferentes circunstancias personales y familiares, y está diseñado para compensar a los contribuyentes con hijos/as menores a cargo, a las personas en situación de dependencia, de edad avanzada o con discapacidad, o a quienes les prestan atención informal, mediante deducciones por ascendientes, descendientes, dependencia y edad. Del mismo modo, el establecimiento de mínimos exentos y de bonificaciones en los rendimientos del trabajo tiene por objeto incentivar el acceso al empleo y garantizar unos ingresos netos suficientes a todas las unidades contribuyentes.

Si bien en nuestro entorno se tiende en general a analizar de forma separada el sistema fiscal y el de protección social (atribuyendo al primero una función recaudatoria y al segundo una función redistributiva y asistencial), lo cierto es que en la mayoría de los países de nuestro entorno se está produciendo una mayor integración de ambas esferas y que tanto los análisis como las reformas de las políticas se refieren al conjunto del sistema fiscal y de protección social (tax benefits system). La ventaja de integrar en mayor medida el sistema fiscal y el de protección social radica en que hace más transparente y coherente el conjunto del sistema, además de eliminar la necesidad de establecer sistemas adicionales de comprobación de recursos para el acceso a las prestaciones selectivas, que pueden resultar intrusivos para las personas en situación de necesidad (Mirrlees et al., 2012).

En ese marco, los gastos fiscales - es decir, la reducción de ingresos públicos como consecuencia de la aplicación de exenciones, gastos deducibles, reducciones, bonificaciones o diferimientos en las liquidaciones y pagos de impuestos - tienen una importancia destacada en los países de la OCDE. Efectivamente, como señala Amenta (1988), “del mismo modo que es imposible entender la vida sin considerar la muerte, es imposible entender la redistribución económica mediante el gasto social sin considerar la fiscalidad. Esto es especialmente cierto para los gastos fiscales, habitualmente conocidos como brechas o agujeros, que residen en las profundidades de la normativa fiscal".

Este modelo, en el que las políticas sociales se desarrollan desde los sistemas de protección social pero también desde el sistema fiscal, presenta algunas limitaciones: 
- Por una parte, introduce en el conjunto del sistema fiscal y prestacional un cierto grado de complejidad y determinadas distorsiones, relacionadas con la mayor o menor tributación a la que se someten las prestaciones económicas públicas, el mayor o menor incentivo que la fiscalidad sobre el trabajo impone en relación con el desempeño de una actividad laboral, o la necesidad de que diversas Administraciones controlen y evalúen los ingresos de las personas para acceder a diversas prestaciones orientadas a la cobertura de una misma contingencia.

- En lo que se refiere a la progresividad del sistema, el modelo de deducciones y desgravaciones establecido beneficia en mayor medida a las rentas medias y altas, y deja fuera de su alcance, fundamentalmente, a las personas que no realizan la declaración de la renta y/o generan una deuda tributaria muy reducida. En la medida en que el efecto máximo de las deducciones fiscales es el de reducir a cero la cuota líquida, y en la medida en que las deducciones no pueden superar la cuota tributaria, cuanto mayor es esa cuota mayor es, en términos absolutos, el beneficio potencial que puede obtenerse de estas figuras impositivas. Quienes no tributan, o quienes lo hacen en muy escasa cuantía, no se ven por lo general beneficiados/as de este tipo de políticas.

En ese contexto, se ha hablado por parte de diversos autores de un Estado de Bienestar oculto que, como explica Noguera (2016), redistribuye la renta de forma paralela al Estado de Bienestar visible o convencional. Se trata de lo que muchos estudiosos llaman "sistema de bienestar fiscal", y que consiste en todas las exenciones, reducciones y deducciones impositivas que la Administración aplica a los contribuyentes, a menudo por motivos similares a los que generan las prestaciones y servicios del Estado de Bienestar tradicional. Noguera cita en ese sentido el clásico ensayo de Titmuss (The Social Division of Welfare), quien señaló que muchas transferencias de renta desde el Estado a los ciudadanos son de hecho pagadas a través del sistema fiscal, de forma que cuando se condicionan a finalidades ligadas con el bienestar social, constituyen prestaciones sociales “ocultas”. Según Noguera (2016):

Titmuss mostró (y muchas investigaciones posteriores confirman) que esta parte del gasto social puede alcanzar un volumen importante en términos de recursos y puede tener impactos distributivos regresivos que pasan desapercibidos en la discusión pública, pero, paradójicamente, suscita escasa atención por parte de los estudiosos del Estado de Bienestar, quienes suelen centrarse en el análisis de los servicios y prestaciones sociales directas.

De acuerdo a los datos de Noguera, el montante de ese Estado del Bienestar oculto alcanzaría en
España los once mil millones de euros ${ }^{2}$. En el caso de la Comunidad Autónoma del País Vasco, solo en lo que se refiere al IRPF, el presupuesto total de gastos fiscales ${ }^{3}$ ascendía en el presupuesto de 2019 a 1.931 millones, a los que habría que añadir en torno a 585 millones correspondientes a las deducciones familiares y personales (que comprenden las deducciones por descendientes, anualidades por alimentos a los hijos, por ascendientes, por discapacidad y por edad) y que por razones técnicas no se incluyen en el presupuesto general de gastos fiscales.

\subsubsection{La integración de impuestos y prestaciones y la naturaleza reembolsable de las deducciones fiscales}

La creciente utilización de deducciones y desgravaciones fiscales para hacer frente a determinadas necesidades sociales no ha supuesto, en general, una mejora en la capacidad redistributiva de los Estados de Bienestar, debido a que, como se ha dicho, los grupos con menor renta no se benefician de las deducciones y desgravaciones convencionales, por no pagar impuestos o por pagarlos en muy escasa medida.

En ese sentido, Ayala y Cantó (2009) señalan que las reducciones impositivas provocan en general una pérdida de la capacidad redistributiva del Estado hacia las rentas más bajas, ya que estas no se benefician de las reducciones de la fiscalidad y se ven penalizadas por el recorte que, a medio o largo plazo, la menor capacidad económica pública provoca en los servicios y prestaciones públicas. En relación con la pobreza infantil, estos autores señalan que "las desgravaciones y deducciones fiscales encaminadas a apoyar a las familias trabajadoras con niños suelen tener efectos nulos o pequeños sobre los ingresos de los hogares con rentas muy bajas que, en general, no están obligados al pago de impuestos sobre la renta, por lo que es importante que las deducciones fiscales sean reembolsables como subsidios para los que no tributan. Si así fuera, estas políticas pueden tener efectos positivos en la reducción de la pobreza infantil” (Ayala y Cantó, 2009: 36).

En ese contexto, algunos países de nuestro entorno han querido hacer frente a las limitaciones de las

${ }^{2}$ Para el cálculo se tienen en cuenta todas aquellas deducciones en la cuota o reducciones en la base imponible del IRPF que están directamente relacionadas con las funciones tradicionales del Estado de Bienestar: educación, sanidad, dependencia, hijos (nacimiento y adopción), ayuda familiar, desempleo, pensiones, invalidez, vivienda y otros gastos similares. El cálculo no incluye los beneficios fiscales que se otorgan por otros conceptos, ni tampoco los que se cobran de forma genérica a nivel personal, como el mínimo vital o la reducción general por rendimientos del trabajo; tampoco se incluye la reducción por las cotizaciones a la Seguridad Social para no incurrir en un supuesto de doble imposición (dado que las pensiones contributivas están ya sujetas a IRPF).

3 El Presupuesto de Gastos Fiscales puede definirse como la cuantificación de la disminución de ingresos tributarios que presumiblemente se producirá a lo largo del año, como consecuencia de la existencia de incentivos fiscales orientados al logro de determinados objetivos de política económica y social. 
deducciones fiscales convencionales, y también de las prestaciones económicas clásicas, mediante el desarrollo de las deducciones o créditos fiscales reembolsables ${ }^{4}$ (refundable tax credits). En líneas generales, estas deducciones se diferencian del resto de las deducciones fiscales en el hecho de que no están limitadas a la deuda tributaria del contribuyente: la deducción reembolsable reduce la deuda con Hacienda hasta cero - como ocurre con el resto de las deducciones-, pero si la deducción es superior a la cuota, la diferencia se convierte en una transferencia neta que se le abona al contribuyente. En algunos de los sistemas aplicados la compensación tiene, hasta un nivel salarial determinado, un carácter progresivo (la deducción crece a medida que aumentan los ingresos salariales) y decreciente a partir de ese umbral (decrece a medida que los ingresos propios aumentan), de forma que, superado el máximo de ingresos salariales fijado, el derecho a la compensación desaparece.

El carácter reembolsable de estas deducciones resulta desde ese punto de vista un elemento esencial, ya que, como explica McCabe (2018), traslada el énfasis político de la lógica de la reducción de impuestos a la lógica de la redistribución, sin renunciar a la lógica de la activación y la rentabilización del empleo (making work pay), en su objetivo de desactivar la llamada “trampa de la pobreza”. La distinción entre ambas lógicas - reducción de impuestos frente a redistribución - remite a otra, omnipresente en el debate sobre las políticas redistributivas, entre el contribuyente por una parte y el perceptor de prestaciones de garantía de ingresos por otra.

Dado su funcionamiento, las deducciones reembolsables se asocian a menudo a la idea del impuesto negativo sobre la renta (INR), que tiene un funcionamiento similar, si bien el INR se plantea desde posicionamientos conceptuales diferentes, en la medida en que pretende sustituir el conjunto de las transferencias sociales por un dispositivo fiscal único, de carácter universal, que puede suponer bien una aportación neta o bien una contribución neta del (o al) contribuyente en función de su situación personal, y no, como en el caso de los créditos fiscales, hacer frente a unas necesidades o situaciones específicas.

En ese marco general, los créditos fiscales reembolsables que se analizan en este artículo tienen tres finalidades básicas, a menudo interrelacionadas:

- Desarrollar las políticas de apoyo a las familias con hijos e hijas, complementando otras prestaciones económicas que puedan existir, y reducir la incidencia de la pobreza infantil.

${ }^{4}$ A lo largo de este artículo, se hace referencia a los tax credits usando, indistintamente, los términos "crédito" o "deducción fiscal".
- En la óptica de la activación $n^{5}$ reducir los desincentivos al empleo que pueden tener aparejados los sistemas ordinarios de rentas mínimas y estimular el acceso al empleo de los perceptores de rentas mínimas.

- Desde esa misma óptica, proteger a los trabajadores de bajos salarios y mejorar las políticas redistributivas dirigidas a ese colectivo, haciendo frente de esa forma a la erosión de la capacidad inclusiva del empleo que supone el fenómeno de los trabajadores pobres o working poors.

Los diferentes sistemas de créditos fiscales existentes se diferencian entre sí en función de la importancia que dan a cada uno de estos objetivos. Si bien es cierto que los tres presiden en general el funcionamiento de los diversos modelos existentes, el énfasis puesto en cada uno de ellos suele ser diferente, lo que se traduce en diseños y modalidades de aplicación diferentes. Del mismo modo, a la hora de evaluar sus resultados, será necesario distinguir si el juicio se refiere a la inclusión laboral de determinados colectivos, a la erradicación de la pobreza infantil, al apoyo a las familias con hijos/as o a la protección de los trabajadores de bajos salarios.

A estos tres objetivos básicos pueden añadir dos finalidades complementarias:

- Por un lado, contribuir a la simplificación, normalización y “legibilidad” del sistema fiscal y prestacional, evitando los elevados niveles de non take up o no recurso a las prestaciones económicas que se registran, los errores y cobros indebidos, o el exceso de gasto en gestión y administración ${ }^{6}$. En lo que se refiere a la normalización del sistema, estos modelos se alejan de los principios de condicionalidad que habitualmente se asocian a las rentas mínimas de inserción y -sin abandonar, lógicamente, su carácter selectivo y condicionado- apuestan por un modelo de garantía de rentas más automático, sencillo y normalizado, en la medida en que se integran en un dispositivo -el fiscal- dirigido al conjunto de la población y se limitan a complementar unos ingresos laborales considerados insuficientes.

- Por otro, contribuir a dotar al sistema fiscal de una mayor progresividad, extendiendo a las rentas más bajas los beneficios que los grupos con rentas más altas han venido obteniendo de las

\footnotetext{
${ }^{5}$ En los países de la OCDE, este tipo de desgravaciones fiscales se enmarca a menudo - aunque no en todos los casos- en un conjunto más amplio de prestaciones condicionadas a la participación en el mercado de trabajo, y están por tanto estrechamente vinculadas a las políticas de activación y, dentro de estas, a las llamadas "políticas de rentabilización del empleo" o making work pay.

${ }^{6}$ Para Eissa y Hoynes (2008), la principal ventaja de establecer un sistema de prestaciones económicas a partir del sistema fiscal reside en la reducción de los costes administrativos, en la medida en que se utilizan los mismos recursos que se emplean para la gestión de los tributos.
} 
rebajas impositivas, y facilitando un tratamiento fiscal más beneficioso a las familias con hijos y/o a los trabajadores de bajos salarios.

Junto a estos elementos, es necesario señalar otras características básicas de este tipo de herramientas:

- Se trata de herramientas fiscales especialmente desarrolladas en los países anglosajones - se han definido como un pilar básico de un emergente modelo "anglosocial" de carácter transoceánico (Clegg, 2015) y muy vinculados a lo que en su momento se conoció como "tercera vía". No debe olvidarse en ese sentido que los principales promotores de estas medidas fueron políticos como Bill Clinton, Tony Blair o Gordon Brown.

- No se trata de prestaciones universales ni incondicionales: a menudo se orientan únicamente a quienes tienen ingresos laborales -en la lógica ya señalada de la activación y el making work pay-y en general se reducen a medida que crecen los ingresos, hasta desaparecer a partir de unos ingresos determinados. Buscan, desde ese punto de vista, incentivar el acceso al empleo de bajos salarios y en pocos casos se orientan a personas inactivas.

- En general, son sistemas complementarios a las prestaciones económicas convencionales, si bien en algunos casos las personas potencialmente beneficiarias han de optar entre un sistema u otro. En cualquier caso, los países que en mayor medida desarrollaron estas medidas, como Reino Unido, las deducciones fiscales eran compatibles con sistemas de garantía de ingresos y de apoyo a las familias con hijos/as muy desarrollados (especialmente en el caso de las prestaciones familiares).

- Se aplican en general como deducciones en la cuota y coexisten con otros beneficios fiscales (mínimos vitales, bonificaciones por trabajo, reducciones por tributación conjunta, exención de determinados ingresos, otras deducciones, etc.), así como con el resto de las características que definen un sistema fiscal determinado (tipos, tramos, mínimos exentos, etc.).

\subsection{Principales experiencias}

Este artículo recoge las características de las principales deducciones fiscales reembolsables existentes en los países de la Unión Europea, así como en Estados Unidos, Canadá y Nueva Zelanda. El informe detalla el funcionamiento y alcance de una veintena de herramientas fiscales que comparten dos elementos básicos: están orientados a compensar diversas necesidades sociales y/o a alcanzar diversos objetivos en materia de políticas sociales - promover el acceso al empleo, proteger a los trabajadores de bajos salarios, compensar los gastos derivados de la crianza o la atención a personas dependientes, etc. - y tienen carácter reembolsable, es decir, pueden ser percibidos como prestación neta cuando el montante de la deducción supera la deuda tributaria. Aunque, en general, las experiencias descritas están actualmente en vigor, se han incluido por su interés algunas referencias -como la Prime pour l'Emploi francesa o las deducciones fiscales británicas- ya derogadas o en proceso de derogación. Para todos los dispositivos analizados se ofrecen datos genéricos sobre su funcionamiento (cuantías máximas, requisitos de acceso, formas de cálculo, personas beneficiarias) y sobre su alcance (gasto, número de beneficiarios, etc.). Aunque se ha intentado describir cada sistema con el mismo nivel de detalle, es evidente que el grado de consolidación de las diferentes herramientas es diferente y también el nivel de información disponible.

En total, se ha recogido información sobre 31 deducciones fiscales diferentes, desarrolladas en doce países:

- Earned Income Tax Credit (EITC) y Child Tax Credit (CTC), en Estados Unidos.

- Working Tax Credit (WTC) y Child Tax Credit (CTC) en Reino Unido.

- Prima por el Empleo, deducción por costes de atención infantil de hijos/as menores de seis años y deducción por adaptación de la vivienda en caso de personas con discapacidad en Francia.

- Deducción por hijo/a cargo (Kinderfreibetrag) en Alemania.

- Deducción para familias numerosas, deducción por alquiler y deducción para trabajadores de bajos salarios (bono de 80 euros) en Italia

- Deducción por maternidad y deducción de familia numerosa, por ascendiente con dos hijos o por personas con discapacidad a cargo en España.

- Deducción por hijo/a cargo (Kinderfreibetrag), deducción por gastos de movilidad laboral (Verkehrsabsetzbetrag), deducción destinada a las familias monoparentales o familias con un solo perceptor/a de ingresos (Alleiverdiener o Alleinerziehrabsetzbetrag) y deducción para personas pensionistas (Pensionistenabsetzbetrag) en Austria.

- Deducción fiscal por gastos de cuidado infantil, deducción para trabajadores de bajos salarios y deducción para personas que tienen ingresos de baja cuantía derivados de actividades profesionales en Bélgica.

- Deducción por hijo/a a cargo en la República Checa.

- Deducción por hijo/a cargo, deducción para trabajadores de bajos salarios, y deducción por intereses hipotecarios en Eslovaquia.

- Crédito fiscal familiar (FTC), crédito fiscal por trabajo (IWTC), crédito fiscal para niños/as de o a 3 años (Best Start Tax Credit) y crédito fiscal familiar mínimo (Minimum Family Tax Credit) en Nueva Zelanda.

- Prime pour l'Emploi o Work bonus, deducción por gastos de atención infantil y deducción por el 
mantenimiento a domicilio de personas mayores de setenta años en la provincia canadiense de Quebec.

\section{Diseño y características de las deducciones fiscales reembolsables: análisis de casos}

\subsection{El caso norteamericano: el Earned Income Tax Credit (EITC) y Child Tax Credit (CTC)}

Estados Unidos es sin duda el país que ha desarrollado en mayor medida el modelo de deducciones fiscales reembolsables, fundamentalmente mediante el Earned Income Tax Credit (EITC) y el Child Tax Credit (CTC). El Earned Income Tax Credit (EITC) norteamericano es, sin duda alguna, el principal referente internacional en lo que a los créditos fiscales reembolsables se refiere, tanto desde el punto de vista de su cobertura y del gasto realizado como de su papel en el sistema de protección social norteamericano. Se trata, además, del dispositivo más evaluado de todos los analizados en esta revisión, tal y como se pone de manifiesto en el siguiente apartado.

Cabe señalar además que, a diferencia de lo que ocurre en Europa, no parece que en Estados Unidos este tipo de sistemas estén siendo cuestionados. En efecto, mientras que el Gobierno conservador británico, como se señala más adelante, ha optado por desmantelar su sistema de deducciones fiscales reembolsables, la Administración norteamericana - al menos hasta la llegada de Donald Trumpreforzó el dispositivo EITC, incrementando las cantidades que pueden percibir las familias con tres o más hijo/as y reduciendo la penalización que, en la práctica, el diseño de la ayuda implicaba para quienes optaban por la declaración conjunta.

Debe señalarse, en cualquier caso, que el modelo norteamericano se caracteriza, de acuerdo McCabe (2018) por una cierta renuencia a la extensión del carácter reembolsable de estas prestaciones y a la existencia de un debate -menos claro en otros países- entre los partidarios de la lógica de la reducción de impuestos y los partidarios de la lógica de la redistribución o la complementación de ingresos. Si en el caso del EITC la lógica redistributiva derivada del carácter reembolsable de la prestación parece claro - redistribución en todo caso orientada únicamente a las personas ocupadas en el mercado de trabajo-, en el caso de la deducción infantil el mecanismo reembolsable ha sido más limitado y ha estado sometido a mayor debate.

\subsubsection{Funcionamiento y principales características del EITC}

Si bien se trata de una prestación introducida en 1975, el desarrollo del EITC se asocia fundamentalmente al mandato de Bill Clinton que, al tiempo que introducía una serie de drásticos recortes en los sistemas tradicionales de garantía de ingresos (SIIS, 1999), reforzaba también el sistema de créditos fiscales, más coincidente con la lógica workfarista y de rentabilización del empleo. Esta deducción o crédito fiscal está fundamentalmente destinada a las familias con hijos/as menores de edad -o que cursan estudios reglados-que perciben ingresos salariales bajos o medios, si bien, aunque en una cuantía mucho menor, también pueden recibir la ayuda las personas solas sin hijos, siempre que perciban ingresos laborales inferiores a una cantidad determinada. El EITC se enmarca por tanto con claridad en la lógica de la activación y en el paradigma del making work pay al que antes se ha hecho referencia.

El funcionamiento del crédito es relativamente sencillo: para cada composición familiar y hasta un ingreso determinado, la ayuda corresponde a un porcentaje del ingreso salarial y crece a medida que crece el salario (phase in); se aplica posteriormente una fase en la que la cuantía se mantiene intacta independientemente del nivel salarial y, una vez alcanzada esa cifra, la cuantía se va reduciendo descontándose de la ayuda máxima una porcentaje determinado de la ayuda, hasta que el derecho a ella desaparece (phase out). La Tabla 1 recoge los principales elementos del sistema: en el caso de una familia con tres hijos/as, si se ingresa un salario de entre 1 y 14.290 dólares, la deducción equivale al $45 \%$ de esa cantidad, con un máximo de 6.431 dólares (que equivalen aproximadamente al $15 \%$ del salario medio norteamericano). Quienes perciben un salario de entre 14.290 y 18.660 dólares reciben esa misma cantidad y, a partir de ahí, se inicia la fase de minoración: en ese caso, la deducción se reduce a un ritmo del $21 \%$. De esa forma, la ayuda se pierde -en el caso de una familia con tres hijos/as a cargo- a partir de ingresos salariales anuales de 49.194 dólares (que equivalen al $118 \%$ del salario medio estadounidense); en el caso de dos hijos/as, el límite asciende a 45.082 ( $110 \%$ del salario medio); en el caso de un solo hijo, 40.320 ( $97 \%$ del salario medio) y en el caso de no tener hijos/as a partir de ingresos de 15.270 dólares (36\% del salario medio).

El Gráfico 1, por su parte, recoge la evolución del total del crédito para tres tipos de composiciones familiares. Como se observa en el gráfico, la cuantía de la deducción crece en el caso de la persona con dos hijos a un ritmo importante hasta los 14.000 euros, de forma que por cada dólar de salario se aplica una deducción fiscal de 40 centavos. A partir de ahí, la deducción se estabiliza en el entorno de los 6.000 dólares, para empezar a reducirse paulatinamente en el entorno de los 18.000 dólares de salario. El derecho a la deducción desaparece cuando el salario alcanza los 45.802 dólares, que equivalen como se ha indicado al $110 \%$ del salario medio norteamericano. 
Tabla 1. Criterios de acceso, cuantías y sistema de cálculo de EITC (2018)*

\begin{tabular}{|c|c|c|c|}
\hline Número de hijos/as & 'Phase in' & Cuantía máxima & 'Phase out' \\
\hline 0 & $\begin{array}{c}1 \text { a } 6.780 \\
7,65 \% \text { del ingreso }\end{array}$ & $\begin{array}{c}6.781 \text { a } 8.490 \\
519\end{array}$ & $\begin{array}{c}8.491 \text { a } 15.270 \\
\text { Cuantía máxima menos } 7,65 \% \text { de la diferencia } \\
\text { entre ingreso y } 8.490\end{array}$ \\
\hline 1 & $\begin{array}{c}1 \text { a } 10.180 \\
34 \% \text { del ingreso }\end{array}$ & $\begin{array}{c}10.181 \text { a } 18.660 \\
3.461\end{array}$ & $\begin{array}{c}18.661 \text { a } 40.320 \\
\text { Cuantía máxima menos } 15,9 \% \text { de la diferencia } \\
\text { entre el ingreso y } 18.660\end{array}$ \\
\hline 2 & $\begin{array}{c}1 \text { a } 14.290 \\
40 \% \text { del ingreso }\end{array}$ & $\begin{array}{c}14.291 \text { a } 18.660 \\
5.716\end{array}$ & $\begin{array}{c}18.661 \text { a } 45.802 \\
\text { Cuantía máxima menos } 21 \% \text { de la diferencia } \\
\text { entre ingreso y } 18.661\end{array}$ \\
\hline 30 más & $\begin{array}{c}1 \text { a } 14.290 \\
45 \% \text { del ingreso }\end{array}$ & $\begin{array}{c}14.290 \text { a } 18.660 \\
6.431\end{array}$ & $\begin{array}{c}18.661 \text { a } 49.194 \\
\text { Cuantía máxima menos } 21 \% \text { de la diferencia } \\
\text { entre ingreso y } 18.661\end{array}$ \\
\hline
\end{tabular}

* Los cálculos están realizados para el caso de declaraciones fiscales individuales. En el caso de las declaraciones conjuntas, se suman 5.680 euros a los niveles que dan acceso a la cuantía máxima, así como al inicio de la fase de minoración.

Gráfico 1. Cuantias garantizadas para diversas composiciones familiares y niveles salariales en el marco del EITC norteamericano (2018)

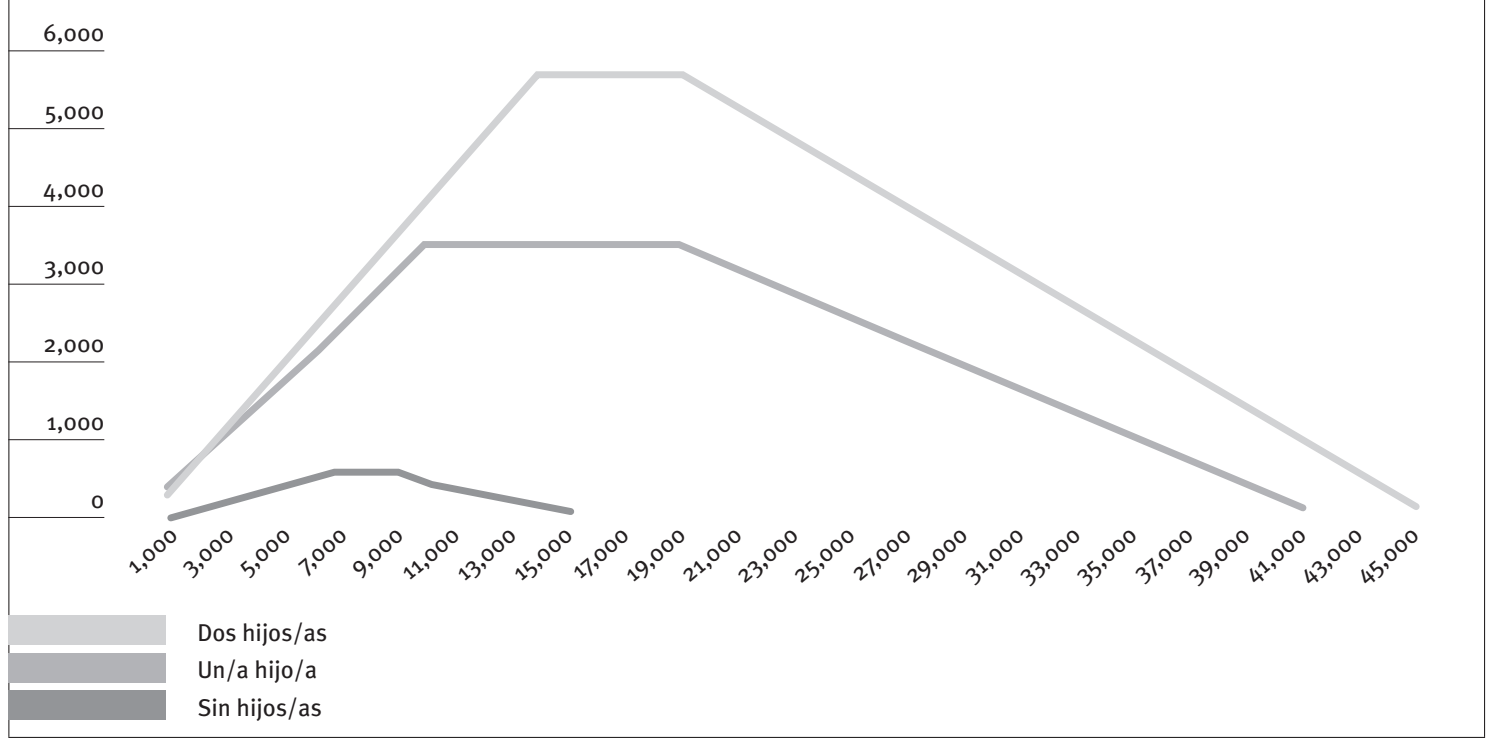

Fuente: Elaboración propia.

\subsubsection{Alcance del EITC}

En 2017, el gobierno norteamericano destinó 68.000 millones de dólares (lo que supone un 0,32 \% del PIB) al EITC. De esa cantidad, el $86 \%$ se percibe como prestación neta y el $14 \%$ como deducción fiscal convencional, lo que pone de manifiesto la importancia del carácter reembolsable de la prestación. El EITC es sin duda el principal programa de lucha contra la pobreza en los Estados Unidos: se calcula, para el año 2016, que se beneficiaron de esta ayuda en torno a 28 millones de contribuyentes, con una deducción media de 2.440 dólares. La cantidad media oscila en cualquier caso entre los 294 dólares anuales de las personas sin hijos/as y los 4.185 de los contribuyentes con tres o más hijos/as. Dado su diseño, el EITC beneficia fundamentalmente a las personas con hijos/as a su cargo, que reciben el $97 \%$ del gasto destinado a esta deducción.
La Tabla 2 recoge, para diversas composiciones familiares, tanto el porcentaje de hogares en relación con su situación respecto al EITC como con las cuantías medias percibidas. Como se observa en ella, el 5,9\% de las familias norteamericanas no acceden a esta deducción por carecer de ingresos laborales y el $77,9 \%$ por percibir ingresos superiores al máximo. El 16,2\% restante se divide entre quienes están en la fase de incremento, sin llegar a la deducción máxima, quienes están en la fase máxima (4,3\% de la población) y quienes están en la fase decremental (9,2\% de la población). La cuantía media percibida es de 3.500 dólares anuales, que asciende a 4.700 entre las familias biparentales con hijos/as. Las diferencias de acceso en función de las características sociodemográficas de las familias son evidentes. 
Tabla 2. Situación en relación con el EITC y cuantía media por tipo de familia (2012)

\begin{tabular}{|c|c|c|c|c|c|c|c|c|}
\hline & \multicolumn{5}{|c|}{ Distribución de la población (\%) } & \multicolumn{3}{|c|}{ Cuantía media (dólares al año) } \\
\hline & $\begin{array}{c}\text { No ingresos } \\
\text { no EITC }\end{array}$ & $\begin{array}{c}\text { Fase de } \\
\text { incremento }\end{array}$ & $\begin{array}{c}\text { Fase } \\
\text { estable }\end{array}$ & $\begin{array}{l}\text { Fase de } \\
\text { reducción }\end{array}$ & $\begin{array}{l}\text { Sí ingresos, } \\
\text { no EITC }\end{array}$ & 'Phase in' & Estable & 'Phase out' \\
\hline Total & 5,9 & 4,3 & 2,7 & 9,2 & 77,9 & 1.600 & 3.500 & 1.900 \\
\hline Unipersonal & 7,2 & 3,8 & 0,7 & 5,2 & 83,1 & 200 & 500 & 200 \\
\hline $\begin{array}{l}\text { Monoparental con } \\
\text { hijos/as }\end{array}$ & 4,6 & 11,9 & 7,6 & 22,1 & 53,9 & 2.500 & 4.100 & 2.500 \\
\hline $\begin{array}{l}\text { Biparental con } \\
\text { hijos/as }\end{array}$ & 1,5 & 3,1 & 5,0 & 16,5 & 73,9 & 3.000 & 4.700 & 2.600 \\
\hline Blancos & 6,9 & 3,0 & 1,7 & 6,6 & 81,8 & 1.300 & 3.100 & 1.700 \\
\hline Afroamericanos & 5,3 & 7,8 & 3,9 & 13,3 & 69,6 & 1.700 & 3.600 & 1.900 \\
\hline Hispanos & 3,1 & 6,9 & 6,3 & 17,8 & 65,8 & 2.000 & 3.900 & 2.100 \\
\hline Estudios básicos & 11,0 & 10,6 & 7,3 & 18,7 & 52,4 & 1.800 & 4.000 & 2.100 \\
\hline Estudios superiores & 3,4 & 1,5 & 0,9 & 4,1 & 90,0 & 1.200 & 2.800 & 1.500 \\
\hline
\end{tabular}

Nota: Elaboración propia a partir de Nichols y Rothstein (2015).

Por otra parte, en la mayor parte de los casos el crédito fiscal se percibe en un pago único en el año posterior al que se realiza la declaración fiscal7. Se estima, por otra parte, que entre el $15 \%$ y el $25 \%$ de los potenciales beneficiarios de la ayuda no la solicitan, ante lo cual se han puesto en marcha por parte de diversas entidades públicas y privadas campañas para incrementar el nivel de acceso a la prestación por parte de la población que puede ser potencialmente beneficiaria.

Los datos de seguimiento del EITC indican además que el acceso a la prestación se plantea a menudo de forma provisional como respuesta a situaciones concretas de necesidad, y no de forma permanente. De hecho, solo el $20 \%$ de los perceptores del EITC entre 1989 y 2006 se beneficiaron de la prestación durante más de cinco años seguidos. El 39\% lo hizo por periodos de entre un año y cuatro y el $42 \%$ durante periodos inferiores al año (aunque no necesariamente durante un solo periodo a lo largo de toda la vida). Se calcula, por otra parte, que en torno a la mitad de los contribuyentes con hijos/as han utilizado este crédito al menos en una ocasión a lo largo de esos 18 años (Carr et al., 2013).

En lo que se refiere al perfil de las personas beneficiarias, Meyer (2010) estima que en torno al $48 \%$ de las familias beneficiarias y el $36 \%$ del gasto se destina a familias monoparentales encabezadas por mujeres; en torno al $8 \%$ del gasto y de los beneficiarios correspondería a hombres solos con hijo/as a cargo y el $38 \%$ del gasto, con el $30 \%$ de

7 Brewer (2010) sugiere que este pago actúa como una paga extraordinaria, que permite a sus beneficiarios la realización de compras extraordinarias y/o satisfacer deudas o gastos pendientes. En el mismo sentido, Nichols y Rothstein (2015) constatan la escasa extensión del cobro anticipado de esta prestación y sugieren también que puede deberse a la preferencia por recibir una paga extraordinaria anual, lo que permite considerar esta prestación como una forma de ahorro que permite financiar desembolsos de cierta cantidad y/o regularizar periódicamente la economía doméstica. las personas usuarias, serían familias biparentales con hijo/as a cargo. Las personas sin hijos/as a cargo, solas o en pareja representan el $25 \%$ de los beneficiarios pero apenas un $3 \%$ del gasto, como antes se ha señalado.

\subsubsection{Child Tax Credit}

Junto al EITC, el sistema norteamericano incluye una deducción fiscal no reembolsable, es decir, que no puede ser percibida como prestación neta. El Child Tax Credit (CTC) es una deducción fiscal de hasta 2.000 dólares por hijo a cargo, dependiendo de los ingresos familiares, de la que se pueden beneficiar, en su cuantía máxima, los contribuyentes con ingresos de hasta 200.000 dólares (400.000 en el caso de las declaraciones conjuntas).

El Child Tax Credit tiene en cualquier caso un componente reembolsable, en la medida en que una parte (conocida como Child Tax Credit adicional) puede obtenerse como prestación neta con un límite de 1.400 dólares anuales. La deducción reembolsable no puede superar el $15 \%$ de los ingresos salariales de la unidad contribuyente, lo que perjudica a los contribuyentes con ingresos más reducidos.

Antes de su reforma (en 2018 se duplicó de 1.000 a 2.000 dólares el montante de la deducción máxima), el gasto asociado al CTC alcanzaba los 52.000 millones de dólares, con 35 millones de familias beneficiarias (casi el $70 \%$ de todas las familias con niño/as de Estados Unidos). Se calcula que en torno a la mitad del gasto corresponde a la parte no reembolsable de la deducción (y constituye por tanto un gasto fiscal) y la otra mitad a la parte reembolsable, abonada como prestación directa. Por decilas, la deducción beneficia al $70 \%$ de las familias del primer decil de ingresos, al $90 \%$ de las del decil segundo y tercero, al $75 \%$ del cuarto y al $5 \%$ del quinto. 


\subsection{El Working Tax Credit (WTC) y el Child Tax Credit (CTC) del Reino Unido}

Aunque está llamado a desaparecer en breve, se mantiene parcialmente vigente a la hora de redactar este artículo el sistema de créditos fiscales británico introducido por el gobierno laborista en 2003, a partir del modelo de Family Credit de 1988 y, sobre todo, del Working Family Tax Credit de 1999. De acuerdo con Clegg (2015), pese a sus dificultades, el sistema de tax credits estuvo en la base de la eficaz estrategia que los laboristas británicos acometieron a finales de los años noventa para la reducción de la pobreza, especialmente entre los niños/as y las personas ocupadas. No es por tanto de extrañar que los créditos fiscales se asocien fundamentalmente con la lucha contra la pobreza infantil y la pobreza laboral.

Los objetivos básicos de estas deducciones eran tres (Gregg, Hurrell y Withaker, 2012):

- Reducir la pobreza infantil.

- Rentabilizar el acceso al empleo y promover la inclusión laboral, reduciendo los desincentivos al empleo e incrementando el poder adquisitivo de los trabajadores de bajos salarios.

- Más allá de la posibilidad de abonar una prestación neta a ciertas familias, introducir un sistema de desgravaciones fiscales para el conjunto de las familias con hijos/as, dotando al sistema fiscal de una mayor progresividad, tras el proceso de individualización tributaria desarrollado en años anteriores en el Reino Unido.

Adicionalmente, es importante destacar el papel que el sistema concedía a los gastos de atención infantil y de conciliación laboral, a la monoparentalidad y a la discapacidad, factores que se tenían en cuenta, en ocasiones de forma muy generosa, a la hora de complementar las cuantías básicas a las que los contribuyentes tenían derecho en el marco de los tax credits británicos. Desde ese punto de vista, los créditos fiscales se enmarcaban claramente en otras políticas sociales sectoriales y contribuían a una mayor integración del sistema tributario y las políticas de discapacidad, conciliación laboral o apoyo a la monoparentalidad.

El sistema se basaba en dos créditos fiscales diferentes, compatibles y acumulables entre sí: el Working Tax Credit (WTC) y el Child Tax Credit (CTC). El primero se dirigía a personas, con o sin hijos/as, con una dedicación laboral mínima, mientras que el segundo -compatible con las prestaciones familiares directas (child benefits) existentes en el Reino Unido- se dirigía a familias, ocupadas o no, con hijos/as a cargo.

Orientado a los trabajadores pobres, el sistema de tax credits británico se diseñó para conciliar el objetivo de redistribución y reducción de la pobreza con otros objetivos más valorados a la derecha del espectro político, como la reducción de la presión fiscal sobre los empresarios, la reducción de la dependencia respecto de las prestaciones económicas y el estímulo de la inclusión laboral (Clegg, 2015). En todo caso, la experiencia de los tax credits británicos constituye sin duda alguna el principal referente desarrollado en el marco europeo para la integración de las políticas fiscales, de activación laboral y de apoyo a las familias. Plenamente enmarcados en el paradigma del making work pay, los tax credit o créditos fiscales fueron ampliamente apoyados y desarrollados por los Gobiernos laboristas, si bien su origen se remonta a varias décadas atrás. De hecho, los sucesivos Gobiernos laboristas hicieron del refuerzo de los créditos fiscales la piedra angular de sus políticas contra la pobreza infantil y para el fomento de la inclusión laboral, con resultados que, como se señala más adelante, pueden considerarse en líneas generales positivos. Llamados a desaparecer tras la llegada de conservadores y liberales al Gobierno, el impacto de los créditos fiscales en las políticas sociales británicas ha sido muy importante, hasta el punto de que, de acuerdo con Gregg, Hurrell y Withaker (2012), representan probablemente el mayor cambio en las políticas sociales británicas de los últimos treinta años.

La experiencia británica resulta además de interés en la medida en que tras la llegada de los Gobiernos conservadores al poder se ha procedido a la sustitución gradual del modelo de créditos fiscales por el denominado crédito universal o universal credit, actualmente en fase de implantación, y que se gestiona como prestación directa desde el ámbito de la Seguridad Social. De hecho, aunque las deducciones fiscales reembolsables siguen siendo percibidas por una parte de la población británica, solo algunos perfiles específicos -las personas con discapacidad que cumplen determinados requisitospueden actualmente presentar nuevas solicitudes. Debido a ese motivo, se recogen en este informe los datos y las características de la prestación en el periodo - primeros años de la década de 2010en que se encontraba plenamente operativa, en la medida en que permite dar cuenta del diseño real de esa deducción.

\subsubsection{Funcionamiento y principales características del WTC y el CTC}

Como se ha indicado previamente, el working tax credit estaba supeditado a la realización por parte de al menos un miembro de la unidad familiar de una actividad laboral mínima, que variaba en función de la composición familiar y de la edad.

Para el cálculo de la cuantía de la deducción, se tenían en cuenta diversos conceptos, como la duración de la jornada laboral realizada, la monoparentalidad, la discapacidad o la existencia de gastos de atención infantil en la unidad familiar. En 2013, las cuantías anuales garantizadas eran las siguientes: 


\begin{tabular}{|l|l|}
\hline Tipo de familia & Requisitos de acceso \\
\hline Familias sin hijos/as & $\begin{array}{l}\text { Al menos } 30 \text { horas semanales de actividad laboral para los mayores de } 25 \text { años; } \\
\text { Al menos } 16 \text { horas de actividad laboral para personas mayores de } 16 \text { años con discapacidad; } \\
\text { Al menos } 16 \text { horas de actividad laboral para personas mayores de } 60 \text { años; }\end{array}$ \\
\hline Familias con hijos/as & $\begin{array}{l}\text { Al menos } 16 \text { horas de actividad laboral para personas mayores de } 16 \text { años a cargo de familias monoparentales; } \\
\text { Al menos } 24 \text { horas de actividad laboral, en conjunto, para parejas con hijos, siempre que al menos una de ellas } \\
\text { trabaje más de } 16 \text { horas. }\end{array}$ \\
\hline
\end{tabular}

Fuente: Elaboración propia.

* Dado que el modelo de créditos fiscales británico está siendo paulatinamente desmantelado, se ha optado por recoger las características de la prestación en el año 2013, antes del inicio de su repliegue.

- Cuantía básica: 1.920 libras.

- Cuantía para parejas y familias monoparentales: 1.970 libras adicionales.

- Complemento por 30 horas de actividad laboral: 790 libras adicionales.

- Complemento por discapacidad: 2.855 euros adicionales.

- Complemento por discapacidad severa: 1.190 euros adicionales.

- Complemento por atención infantil: 175 libras semanales por un niño/a y 300 por dos o más, con un máximo del $70 \%$ del coste del servicio.

A su vez, el Child Tax Credit se concedía a todas las familias con hijos/as menores a cargo. Las cuantías máximas eran las siguientes:

- Cuantía básica: 545 libras.

- Cuantía familiar: 2.720 libras por cada niño/a.

- Complemento por discapacidad: 3.015 libras adicionales por cada niño/a con discapacidad.

- Complemento por discapacidad severa: 1.220 libras adicionales por cada niño/a con discapacidad severa.

Para el cálculo de la cuantía de la ayuda que correspondía a cada familia, se determinaban en primer lugar los elementos de ambos créditos a los que cada familia tenía derecho en función de la composición familiar, la jornada laboral y las características especiales ya señaladas (discapacidad, etc.). Una vez calculada de esa forma la cuantía máxima de la ayuda, se iba minorando en función de los ingresos salariales de la familia, aplicándose para ello las siguientes reglas:

- Las familias sin hijos/as, y sin derecho por tanto al crédito infantil, recibían la deducción en su totalidad hasta que sus ingresos brutos alcanzan las 6.420 libras anuales. A partir de ese nivel salarial, la cuantía de la ayuda se iba reduciendo a razón de 41 peniques por cada libra adicional de ingreso, estableciéndose por tanto una tasa de imposición marginal del $41 \%$. El derecho a la prestación desaparecía a partir de ingresos brutos de unas 13.000 libras.

- Las familias que solo podían acceder al crédito infantil, por no cumplir los requisitos laborales o por tener ingresos superiores a los máximos establecidos para la percepción del Working Tax Credit, recibían la cuantía máxima hasta que sus ingresos superaban los 15.910 euros. Una vez alcanzado ese umbral, la cuantía correspondiente se reducía a una tasa del $41 \%$.

- En el caso de las familias que podían acceder a ambas deducciones, la cuantía se va aminorando a una tasa del $41 \%$ a partir de los 6.420 euros. También en este caso la cuantía básica de la deducción infantil se va reduciendo cuando los demás elementos han desaparecido por completo.

El diseño de los créditos británicos se diferenciaba de otros sistemas en que no existía una fase de incremento de la ayuda (phase in), sino que se mantenía estable - siempre que se cumplieran los requisitos en cuanto a horas trabajadas- hasta que se iniciaba la fase de aminoración (phase out).

El pago de la prestación se realizaba de forma mensual. Los cálculos se realizan en función de la situación actual de la familia (número de hijos, jornada laboral, etc.) y de los ingresos familiares del año precedente. A lo largo del año, pueden notificarse los eventuales cambios que se vayan produciendo, por ejemplo en los ingresos salariales. Al final del año se realiza un ajuste en las cantidades señaladas en el caso de que la diferencia entre los ingresos del año precedente y los del ejercicio en cuestión difieran en un montante determinado, teniéndose en cuenta tales cambios cuando superan, en un sentido u otro, un montante determinado (income rise e income fall disregard). En el caso de que la deducción se reciba como ayuda neta, se incorpora normalmente a la nómina de la persona asalariada, en forma de adelanto empresarial, que posteriormente es compensado a la empresa por el servicio de Hacienda. Existe también la posibilidad, en cualquier caso, de que la ayuda pueda ser percibida por la persona que no trabaja.

\subsubsection{Alcance del WTC y el CTC}

Como se ha señalado en el apartado introductorio, el impacto de los créditos fiscales se analiza con detalle en el punto siguiente. En cualquier caso, a la hora de describir sus características, cabe destacar el peso de estas dos ayudas en el marco del sistema fiscal y prestacional británico: en 2010 se destinaron 
a estas dos prestaciones $\mathbf{2 8 . 5 0 0 ~ m i l l o n e s ~ d e ~ e u r o s , ~}$ que representan el $1,75 \%$ del PIB británico y un gasto por habitante de casi 527 euros. En ese año, se beneficiaron de la ayuda 6,2 millones de familias, casi una cuarta parte del total de familias británicas. Como se observa en la Tabla 4, el $68 \%$ del gasto se orientaba a familias con ingresos salariales y con hijos/as.

Tabla 4. Alcance de los 'tax credits' en el Reino Unido por situación de las familias (2010)

\begin{tabular}{|l|c|c|}
\cline { 2 - 3 } \multicolumn{1}{c|}{} & $\begin{array}{c}\text { Familias } \\
\text { beneficiarias } \\
\text { (miles) }\end{array}$ & $\begin{array}{c}\text { Gasto } \\
\text { (millones de } \\
\text { libras) }\end{array}$ \\
\hline Familias sin empleo & 1.462 & 7.600 \\
\hline $\begin{array}{l}\text { Familias con empleo y } \\
\text { con hijos/as }\end{array}$ & 4.302 & 19.600 \\
\hline $\begin{array}{l}\text { Familias con empleo y sin } \\
\text { hijos/as }\end{array}$ & 544 & 1.300 \\
\hline Total & 6.308 & 28.500 \\
\hline
\end{tabular}

Fuente: Gregg, Hurrell y Withaker, 2012.

Cabe señalar, por otra parte, la elevada cuantía de los créditos y su extensión, especialmente entre las familias monoparentales. Como se observa en la tabla, accedían a estas ayudas el $80 \%$ de las familias monoparentales y el $54 \%$ de las parejas con descendencia. La cuantía media ascendía a 69 libras semanales - para el conjunto de las familias-, que equivalían en la época a 320 euros mensuales. En el caso de las familias monoparentales, la ayuda media alcanzaba los 500 euros mensuales.

Tabla 5. Alcance de los 'tax credits' en el Reino Unido por tipo de familia (2010)

\begin{tabular}{|l|c|c|}
\cline { 2 - 3 } \multicolumn{1}{c|}{} & $\begin{array}{c}\text { Cobertura } \\
\text { (\% de familias } \\
\text { perceptoras) }\end{array}$ & $\begin{array}{c}\text { Cuantía } \\
\text { media (libras } \\
\text { semanales) }\end{array}$ \\
\hline Familias monoparentales & 80 & 97 \\
\hline Parejas con hijos/as & 54 & 58 \\
\hline Solteros/as sin hijos/as & 10 & 65 \\
\hline Parejas sin hijos/as & 2 & 44 \\
\hline Total familias & 24 & 69 \\
\hline
\end{tabular}

Fuente: Gregg, Hurrell y Withaker, 2012.

Las evaluaciones realizadas indican, por otra parte, que pese a la notable cobertura de estos créditos y sus relativamente amplios criterios de acceso, el gasto realizado se centraba particularmente en los grupos de renta menos favorecidos. De acuerdo a los datos de Gregg, Hurrell y Withaker (2012), en torno al $25 \%$ de las familias más pobres en función de sus ingresos propios (es decir, hasta el percentil 25 en la escala de la distribución de la renta antes de impuestos), recibían a través de este sistema una prestación neta, en la medida en que el balance entre la deuda tributaria y la deducción era negativa.

\subsection{Deducciones fiscales en Francia: la experiencia de la Prime pour l'Emploi}

Se analizan a continuación tres deducciones fiscales reembolsables existentes en Francia, si bien la primera de ellas -la Prima por el Empleo- fue eliminada en 2015, en el marco de la reestructuración del sistema francés de garantía de ingresos. La prima por el empleo estaba orientada a los trabajadores de bajos salarios, que desde 2009 se beneficiaban de un tratamiento específico en el marco de la renta garantizada francés (RSA). Las otras dos deducciones, vigentes en la actualidad, compensan los gastos derivados de la atención infantil y la adaptación de viviendas de personas mayores o con discapacidad.

\subsubsection{La experiencia fallida de la Prime pour l'Emploi}

La Prima por el Empleo (Prime pour l'Emploi) fue introducida en 2001 por el Gobierno del socialista Lionel Jospin y resultó desde sus inicios un dispositivo secundario en el conjunto del sistema francés de garantía de rentas. De hecho, la cuantía de la prestación y sus condiciones de acceso fueron congeladas en 2009, con la introducción del RSA, y la deducción fue eliminada en 2015, debido al escaso apoyo político cosechado. Se le atribuía en ese sentido una excesiva complejidad y una capacidad redistributiva muy limitada. Se detallan en cualquier caso algunos elementos básicos de esta deducción, tal y como funcionaba en el momento de su derogación, al objeto de conocer su funcionamiento y efectos.

La percepción de esta prestación estaba sujeta al cumplimiento de tres requisitos:

- Ingresos bajos. La unidad de convivencia debía contar con ingresos inferiores a 16.251 euros para las personas solas y 32.498 euros para las parejas, a las que se sumaban 4.490 euros por cada menor a cargo. En el caso de una pareja con dos hijos/as, los ingresos anuales no podían superar por ejemplo los 41.478 euros.

- Activación laboral. Al menos un miembro del hogar debía haber desempeñado una actividad laboral durante el año.

- Ingresos salariales bajos. Los ingresos salariales anuales derivados de esa actividad debían superar los 3.743 euros y no podían ser superiores a 17.451, en el caso de una persona sola o de dos personas activas, o 26.572 en el caso de una persona activa que convive con otra inactiva.

Como en el caso norteamericano, el montante de la deducción se incrementaba inicialmente a medida que se incrementaban los ingresos salariales (phase in) y se reducía progresivamente a partir de un nivel salarial determinado (phase out). La cuantía se calculaba en función de una serie de reglas que variaban en relación al salario percibido 
y el número de personas integrantes de la unidad familiar. Grosso modo, la deducción crecía a la par que el salario hasta salarios brutos cercanos a los mil euros mensuales. A partir de ese nivel salarial, la prestación comenzaba a reducirse para desaparecer una vez se superan los 26.572 euros de ingresos anuales, en el caso de unidades bipersonales en las que solo una persona trabaja y en el de personas solas con hijos/as a cargo.

En 2011, se beneficiaron de esta prestación un total de 6,7 millones de unidades familiares (en torno al $18 \%$ del total), con una percepción media de 450 euros por unidad familiar. El gasto total ascendió a poco más de 3.000 millones de euros, que suponen el $0,15 \%$ del PIB y un gasto por persona de unos 46 euros. Durante los últimos años de vigencia de la prestación se fue reduciendo claramente tanto el gasto como el número de perceptores, debido a la congelación de los criterios de acceso (en 2008, el número de unidades beneficiarias fue de 9 millones y el gasto total de 4.500 millones de euros).

\subsubsection{Deducciones fiscales por costes de atención infantil y por adaptación de vivienda en caso de discapacidad}

Desaparecida la Prima por el Empleo, Francia cuenta en la actualidad con dos deducciones fiscales reembolsables de cierta entidad:

- La deducción por costes de atención infantil de hijos/as menores de seis años reduce la deuda tributaria en la cuantía correspondiente al $50 \%$ de los costes de atención infantil abonados a lo largo de ejercicio, con un coste máximo de 2.300 euros anuales, lo que implica que la deducción máxima no puede superar los 1.150 euros anuales.

- La deducción por adaptación de la vivienda en caso de personas con discapacidad equivale al $25 \%$ de los gastos realizados, con un límite de 5.000 euros en el caso de una persona sola y de 10.000 en el caso de una pareja que realiza una declaración conjunta.

\subsection{Deducciones fiscales en Alemania}

Alemania no cuenta con deducciones fiscales reembolsables propiamente dichas (Gallego y Harnisch, 2008). El funcionamiento de la prestación por hijo a cargo y su relación con el sistema fiscal permite sin embargo hablar también en este caso de un modelo de integración de las políticas sociales y fiscales de gran interés.

El sistema alemán se caracteriza por la integración de las desgravaciones fiscales infantiles y las ayudas directas por hijo/a a cargo, que conforman en la práctica un sistema unificado. Alemania cuenta con una prestación infantil directa (Kindergeld) de carácter universal y de cuantía elevada -184 euros mesuales en el caso del primer hijo-y una desgravación fiscal por hijo/a cargo denominada Kinderfreibetrag. En primera instancia, todas las familias con hijos/as reciben mensualmente la prestación económica y no se les aplica durante el ejercicio fiscal ninguna desgravación o deducción por sus responsabilidades familiares, de forma que a los contribuyentes con y sin hijos se les aplican los mismos tipos, en función de su renta, y se les practican las mismas retenciones. Al finalizar el ejercicio, la administración tributaria calcula el importe de la deducción que corresponde a cada contribuyente y aplica a cada uno la opción económicamente más conveniente (prestación directa o deducción fiscal).

Para la mayor parte de las familias, la prestación económica es superior a la deducción a la que tiene derecho, por lo que no se aplica esa deducción y mantiene las cantidades percibidas como anticipo en concepto de ayuda. Se estima que solo el $5 \%$ de las familias alemanas recurren a la deducción fiscal. La prestación actúa así como una deducción fiscal mensual y, al finalizar el ejercicio, la diferencia entre la deducción a la que se hubiera tenido derecho y la prestación efectivamente recibida sería la transferencia neta que realiza el sistema fiscal. En algunos casos, sin embargo, la deducción resulta más ventajosa: en ese caso, el contribuyente se beneficia de la misma y la ayuda percibida se computa como un abono anticipado de esa deducción.

\subsection{Deducciones fiscales reembolsables en Italia}

Italia introdujo en 2008 dos deducciones fiscales reembolsables, la primera está orientada a las familias numerosas (con al menos cuatro hijos/as a cargo) y la segunda a las personas que viven en régimen de alquiler:

- La deducción para familias numerosas asciende a 1.200 euros anuales para el conjunto de la unidad familiar, y se concede a partir del nacimiento del cuarto/a hijo/a.

- La deducción por alquiler tiene también carácter reembolsable y está orientada a inquilinos sujetos a contratos de alquiler controlado (contratti convenzionali). Asciende a 495,8 euros si los ingresos de la persona contribuyente son inferiores a 15.493,71 euros y 247,90 euros si se sitúan entre 15.493 .71 y 30.987 .41 euros.

Además, el Gobierno de Mateo Renzi introdujo en 2014 una deducción fiscal denominada "bono de 80 euros", para contribuyentes con ingresos de entre 8.174 y 26.600 euros anuales. El bono se abona de forma mensual y tiene una cuantía máxima de 960 euros al año. La cuantía de 960 es uniforme para los ingresos de hasta 24.600 euros anuales, aplicándose hasta los 26.600 una reducción progresiva de acuerdo a la siguiente fórmula:

Deducción $=960 *[26.600 \text {-ingresos) } / 2000]^{*}$ (días de trabajo/365) 
En 2015, el gasto total destinado a esta prestación ascendió a 9.200 millones de euros, que suponen un $0,56 \%$ del PIB italiano. De acuerdo a los cálculos de la Comisión Europea (Astarita et al., 2016), el bono incrementa el ingreso familiar disponible per cápita un $1,11 \%$, con porcentajes que oscilan entre el $1,86 \%$ en la tercera decila de ingresos y el o,28\% en la última. Además, la medida reduce la tasa de pobreza en o,6 puntos porcentuales y el índice de Gini en 0,25.

\subsection{Deducciones fiscales reembolsables en España}

\subsubsection{Deducciones fiscales reembolsables en el territorio español de régimen común}

El territorio de régimen común español cuenta también con una serie de deducciones fiscales reembolsables a las que pueden acceder, por una parte, las mujeres ocupadas con hijos/as menores de tres años y, por otra, las familias numerosas y las que tienen ascendientes o descendientes con discapacidad. En ambos casos se trata de una deducción parcialmente reembolsable que puede ser percibida de forma anticipada y en pagos mensuales.

- La deducción por maternidad minora la cuota del IRPF y se aplica a las mujeres con hijo/as menores de tres años que realicen actividades por cuenta propia o ajena y que estén dadas de alta en la Seguridad Social. La deducción por maternidad es de hasta 1.200 euros anuales por hijo menor de tres años y se calcula de forma proporcional al número de meses en que se cumplan de forma simultánea los requisitos, teniendo como límite para cada hijo el importe íntegro sin bonificaciones de las cotizaciones y cuotas totales a la Seguridad Social y mutualidades devengadas en cada período impositivo con posterioridad al nacimiento 0 adopción. Los contribuyentes con derecho a la aplicación de la deducción por maternidad pueden solicitar a la Agencia Estatal de Administración Tributaria su abono de forma anticipada por cada uno de los meses en que estén dados de alta en la Seguridad Social o mutualidad.

- La deducción de familia numerosa, por ascendiente con dos hijos o por personas con discapacidad a cargo, asciende a $\mathbf{1 . 2 0 0}$ euros anuales en el caso de las familias numerosas y monoparentales con dos o más hijo/as, y a una cantidad idéntica por cada descendiente 0 ascendiente con discapacidad. Las deducciones se calculan de forma proporcional al número de meses en que se cumplan de forma simultánea los requisitos previstos, y tienen como límite para cada una las cotizaciones y cuotas totales a la Seguridad social y mutualidades devengadas en cada periodo impositivo. La deducción puede ser percibida de forma anticipada, mediante un pago mensual.

De acuerdo a los datos de la Agencia Tributaria española, en 2016 el gasto total destinado a estas deducciones ascendió a 1.708 millones de euros, siendo las deducciones por maternidad
(758 millones) y por familia numerosa (620 millones) las que supusieron un mayor gasto. El gasto total equivale al 2,5\% de la cuota líquida total del IRPF. El importe medio de las deducciones es en todos los casos cercano a los mil euros anuales. Es importante también señalar que las 831.963 deducciones por maternidad cubren al $66,1 \%$ de los niños/as nacidos/as en España entre 2014 y 2016.

Tabla 6. Alcance de las deducciones fiscales en España por tipo de deducción en 2016 (cifras en euros)

\begin{tabular}{|l|c|c|c|}
\cline { 2 - 4 } \multicolumn{1}{c|}{} & Número & Importe & $\begin{array}{c}\text { Importe } \\
\text { medio }\end{array}$ \\
\hline Maternidad & 831.963 & 758.733 .673 & 912 \\
\hline $\begin{array}{l}\text { Descendientes con } \\
\text { discapacidad a cargo }\end{array}$ & 278.604 & 288.997 .872 & 1.037 \\
\hline $\begin{array}{l}\text { Ascendientes con } \\
\text { discapacidad a cargo }\end{array}$ & 35.566 & 39.501 .164 & 1.111 \\
\hline Familia numerosa & 634.623 & 620.920 .214 & 978 \\
\hline Total & 1.780 .756 & 1.708 .152 .923 & 959 \\
\hline
\end{tabular}

Fuente: Estadística de los declarantes del IRPF, Agencia Tributaria.

De acuerdo a Ayala y Paniagua (2017), pocos análisis examinan el impacto de la deducción por maternidad española desde el punto de vista de la natalidad o de la reducción de la pobreza. Sus efectos redistributivos son en cualquier caso escasos debido a su escasa focalización (se orienta a todas las madres que abonan al menos 100 euros mensuales en cotizaciones sociales). Sin embargo, algunos estudios (Azmat y González, 2010) han hallado un impacto importante de esta prestación sobre la fertilidad (casi un $5 \%$ ) y sobre la tasa de empleo de las mujeres potencialmente demandantes (en torno a un $2 \%$ ).

\subsubsection{Las deducciones anticipadas en Navarra}

El impuesto sobre la renta de la Comunidad Foral de Navarra también incorpora una deducción anticipada para las personas que perciben diversas modalidades de pensiones que responden al concepto de deducción fiscal reembolsable, en la medida en que la deducción se percibe de forma íntegra, y anticipada, por parte de todas las personas con derecho a ella, independientemente de la cuota tributaria correspondiente.

Se trata de una deducción que se detrae de la cuota diferencial del IRPF en las declaraciones de renta de las personas que perciben determinadas pensiones $y$ reúnen los requisitos establecidos. Tiene como efecto mayoritariamente que se tenga que devolver a las personas afectadas la cuantía resultante. La cuantía de la deducción es la diferencia negativa entre la cuantía mínima anual fijada para cada clase de pensión y los umbrales establecidos para cada tipo de pensión.

Las deducciones por pensiones se aplican en Navarra a las personas perceptoras de las siguientes pensiones: 
- Pensiones de viudedad con derecho a complementos por mínimos de los artículos 59 y 60 del Texto Refundido de la Ley General de la Seguridad Social.

- Pensiones de viudedad sin derecho a complementos por mínimos (pensiones superiores a la cuantía mínima anual fijada para la clase de pensión de que se trate e inferior al umbral establecido).

- Pensiones de viudedad del Seguro Obligatorio de Vejez e Invalidez (SOVI).

- Pensiones contributivas de jubilación con derecho a complementos por mínimos de la Seguridad Social.

- Pensiones contributivas de jubilación sin derecho a complementos por mínimos (pensiones superiores a la cuantía mínima anual fijada para la clase de pensión de que se trate e inferior al umbral establecido).

- Pensiones de jubilación del Seguro Obligatorio de Vejez e Invalidez (SOVI).

- Pensiones no contributivas de jubilación cuyo titular reúne los requisitos para tener derecho a la renta garantizada (en lugar de esta se percibirá la deducción adicional).

Las cuantías previstas se recogen en la siguiente tabla:

Tabla 7. Tipos y cuantías de las deducciones fiscales en el IRPF de la Comunidad Foral de Navarra

\begin{tabular}{|l|l|}
\hline Tipo de pensión & Deducción anual (en euros) \\
\hline $\begin{array}{l}\text { Pensiones de viudedad con } \\
\text { derecho a complementos por } \\
\text { mínimos }\end{array}$ & $\begin{array}{l}\text { Entre } 978 \text { y } 3.145 \\
\text { dependiendo de la edad }\end{array}$ \\
\hline $\begin{array}{l}\text { Pensiones de viudedad sin derecho } \\
\text { a complementos por mínimos }\end{array}$ & 420 \\
\hline $\begin{array}{l}\text { Pensiones de viudedad del Seguro } \\
\text { Obligatorio de Vejez e Invalidez } \\
\text { (SOVI) }\end{array}$ & 4.193 \\
\hline $\begin{array}{l}\text { Pensiones contributivas de } \\
\text { jubilación con derecho a } \\
\text { complementos por mínimos }\end{array}$ & $\begin{array}{l}\text { Entre } 428 \text { y 1.463, } \\
\text { el tipondiendo de la edad y y dad familiar }\end{array}$ \\
\hline $\begin{array}{l}\text { Pensiones contributivas } \\
\text { de jubilación sin derecho a } \\
\text { complementos por mínimos }\end{array}$ & Sin desarrollar \\
\hline $\begin{array}{l}\text { Pensiones de jubilación del Seguro } \\
\text { Obligatorio de Vejez e Invalidez } \\
\text { (SOVI) }\end{array}$ & $3.642,80$ \\
\hline $\begin{array}{l}\text { Pensiones no contributivas de } \\
\text { jubilación cuyo titular reúne los } \\
\text { requisitos para tener derecho a la } \\
\text { Renta Garantizada }\end{array}$ & $\begin{array}{l}2.035 \text { (una persona) } \\
6.355 \text { (tres persona }\end{array}$ \\
\hline
\end{tabular}

El cobro anticipado se realiza de forma mensual en el ejercicio correspondiente al año de la declaración -sin decalaje temporal, por tanto-y se prevé únicamente para las pensiones de viudedad con derecho a complementos por mínimos, las pensiones de viudedad del Seguro Obligatorio de Vejez e Invalidez (SOVI) y las pensiones no contributivas de jubilación cuyo titular reúne los requisitos para tener derecho a la renta garantizada. El anticipo se solicita en los servicios sociales de base o en el propio Departamento de Derechos Sociales, se abona por parte del Departamento de Hacienda y se computa como gasto fiscal. El cobro anticipado implica la no realización de la deducción en caso de realizarse declaración de IRPF.

La Tabla 8 recoge el número de contribuyentes que se vieron beneficiados de las deducciones por pensiones en el IRPF de Navarra entre 2015 y 2017, así como el montante total de esas deducciones y su porcentaje en relación con el conjunto del gasto fiscal en deducciones. Como se observa en ella, tras los cambios normativos realizados en 2016, en 2017 se beneficiaron de esta deducción cerca de 15.000 personas, con un gasto de 12,9 millones de euros, frente a los 2,5 de 2015.

Tabla 8. Número de declarantes e importe de las deducciones por pensiones en la Comunidad Foral de Navarra

\begin{tabular}{|l|c|c|c|}
\cline { 2 - 4 } \multicolumn{1}{c|}{} & $\mathbf{2 0 1 5}$ & $\mathbf{2 0 1 6}$ & $\mathbf{2 0 1 7}$ \\
\hline Número de declarantes & 9.232 & 9.101 & 14.636 \\
\hline Importe (millones de euros) & 2,59 & 3,12 & 12,90 \\
\hline
\end{tabular}

Fuente: Elaboración propia a partir de la Memoria del Departamento de Hacienda del Gobierno de Navarra.

\subsection{Deducciones fiscales reembolsables en Austria}

Austria cuenta con diversos mecanismos que cabe enmarcar en el ámbito de las deducciones fiscales reembolsables orientadas a la compensación de necesidades sociales:

- Por una parte, además de su sistema de ayudas universales a las familias y de ciertas reducciones en la base del impuesto por el coste de la crianza (Kinderfreibetrag), Austria cuenta desde 2009 con un crédito fiscal reembolsable (Kinderabsetzbetrag), que asciende a 58 euros mensuales por cada hijo/a y que se abona mediante transferencia, junto a la prestación por hijo/a cargo. De esta forma, las familias reciben una prestación directa (que oscila en función de la edad entre 114 y 165 euros), así como la deducción fiscal a la que se ha hecho referencia. Se trata de una deducción anticipada, que se aplica también a las personas que no tributan por su renta o que lo hacen en escasa cuantía.

- En lo que se refiere al empleo de bajos salarios, hasta 2015 Austria contaba con el Arbeitnehmerabsetzbetrag, una deducción fiscal reembolsable orientada a trabajadores/as de bajos salarios, con forma de impuesto negativo. A partir de ese año, se crea una deducción por gastos de movilidad laboral (Verkehrsabsetzbetrag) de 400 euros anuales, que tiene carácter de impuesto negativo en determinados casos (se aplica un límite del $50 \%$ de las cotizaciones realizadas a lo largo del año por diversos conceptos). 
- Austria dispone además de una deducción fiscal destinada a las familias monoparentales o familias con un solo perceptor/a de ingresos (Alleiverdiener y Alleinerziehrabsetzbetrag) ${ }^{8}$. En tales casos, la deducción asciende a 494 euros para el primer hijo/a, 669 por dos hijos y 220 euros adicionales a partir del tercero. Existe además, junto estas dos deducciones, otra que puede solicitarse por parte de los/as progenitores/as que abonan pensiones por alimentos, que asciende a entre 29 y 58 euros mensuales, en función del número de hijos/as.

- Por último, cabe hacer referencia a la deducción fiscal para personas pensionistas (Pensionistenabsetzbetrag), que tiene un carácter parcialmente reembolsable.

\subsection{Deducciones fiscales reembolsables en Bélgica}

En la actualidad, Bélgica cuenta con tres deducciones fiscales reembolsables orientadas a la compensación de necesidades sociales:

- Una deducción fiscal por gastos de cuidado infantil, introducida en 2002. La deducción se refiere a los gastos de cuidado infantil de niños/as de hasta 12 años, siempre que no superen los 11,2 euros por niño y por día de cuidado, independientemente de la duración de la estancia. La deducción asciende al $45 \%$ del gasto realizado.

- Una deducción fiscal para trabajadores de bajos salarios introducida en 2011. La deducción tiene una cuantía máxima de 670 euros anuales y se calcula en función de un porcentaje determinado de las cotizaciones sociales para trabajadores/as de bajos salarios establecido en el marco de la Seguridad Social.

- Una deducción fiscal orientada a las personas que tienen ingresos de baja cuantía derivados de actividades profesionales, así como a determinadas categorías de trabajadores/as del sector público, introducida en 2001. La deducción máxima asciende a 780 euros anuales y se aplica a ingresos de entre 5.200 y 22.600 euros anuales.

\subsection{Deducciones fiscales reembolsables en la República Checa}

La República Checa cuenta desde 2005 con una deducción fiscal reembolsable por hijo/a a cargo, que asciende a 522 euros anuales por el primer hijo/a, 741 por el segundo/a y 943 por el tercero/a, con un máximo de 2.300 euros por cada ejercicio fiscal. La deducción se refiere a los hijos/as menores de edad $y$ a los menores de 26 años que cursan estudios reglados, y solo puede ser solicitada por uno de anuales. los dos progenitores. La deducción tiene carácter selectivo, en la medida en que se aplica únicamente a personas con ingresos superiores a seis veces el salario mínimo interprofesional.

\subsection{Deducciones fiscales reembolsables en Eslovaquia}

Eslovaquia cuenta también con una deducción fiscal por hijo/a a cargo, similar a la que existe en la vecina República Checa, así como con una deducción fiscal reembolsable destinada a trabajadores de bajos salarios y otra por gastos de intereses hipotecarios:

- Como en el caso checo, la deducción fiscal por hijos/a a cargo está reservada a personas empleadas con salarios superiores a seis veces el salario mínimo interprofesional y asciende a 21 euros mensuales por hijo/a, que se abonan de forma mensual.

- El segundo crédito, introducido en 2009, está orientado a los trabajadores de bajos salarios. Para beneficiarse de este crédito los ingresos anuales deben ser de al menos seis veces el salario mínimo y debe haberse tenido una actividad laboral al menos durante seis meses durante el año.

- La deducción fiscal por gastos hipotecarios asciende a 400 euros anuales y se destina a personas menores de 35 años, con ingresos inferiores a 1,3 veces el salario mínimo y solo se puede percibir durante cinco años consecutivos.

\subsection{Deducciones reembolsables en Oceanía: la experiencia de Nueva Zelanda}

Nueva Zelanda introdujo entre 2004 y 2007 un paquete de créditos fiscales familiares, claramente inspirados en las experiencias británica y norteamericana, si bien con diferencias importantes en cuanto al diseño de la prestación. Enmarcados también en la filosofía de la activación y del making work pay, se trata de créditos exclusivamente dirigidos a las familias con hijos/as y orientados a conseguir tres objetivos concretos: a) rentabilización del empleo; b) garantía de un ingreso adecuado para las familias con hijos/as y reducción de la pobreza infantil; y c) modificación del sistema de garantía de ingresos, al objeto de ofrecer unos apoyos más activos para la inserción laboral (Dalgety, 2010).

El sistema neozelandés es, en realidad, un paquete conformado por cuatro créditos fiscales diferentes, todos ellos dirigidos a familias con hijos/as: el crédito fiscal familiar (Family Tax Credit), el crédito fiscal mínimo familiar (Minimum Family Tax Credit), el crédito fiscal por trabajo (In Work Tax Credit) y el crédito fiscal para niños de o a 3 años (Best Start Tax Credit). Todos ellos pueden ser compatibles entre sí si se cumplen las condiciones de acceso, y cada uno de ellos tiene umbrales de acceso y cuantías diferentes. 
- El crédito fiscal familiar (FTC) se abona a todas las familias con hijo/as con ingresos inferiores a una cantidad determinada. La cuantía oscila entre los 4.575 y los 5.878 dólares neozelandeses y se reduce a una tasa del $25 \%$ a partir de ingresos superiores a los 42.700 dólares, de forma que el derecho a la deducción desaparece a partir de ingresos superiores a los 65.000 dólares.

- El crédito fiscal por trabajo (IWTC) requiere una dedicación laboral mínima (20 horas semanales en el caso de las familias monoparentales, 30 horas, en conjunto, en el caso de las biparentales), estableciéndose además un nivel de renta máximo. Se destina a familias con hijos/as y asciende, en el caso de tener menos de tres hijos/as, a un máximo 290 dólares mensuales.

- El crédito fiscal parental (Best Start Tax Credit) se destina únicamente a los gastos que se producen durante los tres primeros años de vida de los hijos/as. El montante máximo de la deducción es de 3.120 dólares anuales para familias con ingresos inferiores a 79.000 dólares. La cuantía va reduciéndose, por tramos, hasta desaparecer a partir de ingresos superiores a los 93.858 dólares.

- Por su parte, el crédito fiscal familiar mínimo se paga a las familias con ingresos inferiores a 26.156 dólares netos y en los que al menos una persona desarrolla una actividad laboral mínima, y garantiza unos ingresos mínimos de casi $\mathbf{2 . 0 1 2}$ dólares mensuales para esas familias. El objetivo de este crédito es facilitar la transición de las personas perceptoras de prestaciones de garantía de ingresos al mundo laboral.

En lo que se refiere a la forma de pago, las cuantías se abonan habitualmente de forma quincenal. En cuanto al alcance, se calcula que el montante por contribuyente - sumadas las diferentes deducciones a las que una familia puede tener derecho- ascendió en 2016 a 6.768 euros, con un total de 335.000 familias beneficiarias, lo que supone un gasto total de 2.200 millones de dólares (o,8\% del PIB).

\subsection{La experiencia canadiense: las deducciones fiscales de Quebec}

Canadá es uno de los países que ha desarrollado en mayor medida modelos de deducciones fiscales reembolsables, tanto a nivel federal como provincial, y tanto en el ámbito de las políticas de familia como en el de la protección a los trabajadores/as de bajos salarios. El Gobierno canadiense introdujo ya en los años setenta una deducción fiscal reembolsable por hijo/a a cargo, apoyada por parte de determinados sectores sobre la base de que permitía reducir la dependencia respecto a las prestaciones sociales convencionales (McCabe, 2018). Más adelante, en 2007, Canadá introdujo a nivel federal su Working income tax benefit, con el objetivo fundamental de incentivar el acceso al empleo de las personas con bajos salarios, así como el de evitar la trampa de la pobreza. También en este caso la lógica de la redistribución -0, al menos, de la compatibilización y complementación de ingresos- se imponía a la lógica de la reducción de la presión fiscal. Con un funcionamiento similar al del EITC norteamericano, el crédito fiscal federal canadiense se aplica de forma uniforme en la mayor parte de las provincias y territorios canadienses, si bien en algunos de ellos -Alberta, Quebec, Columbia Británica y Nunavut-se establecen cuantías y criterios de acceso diferentes. A su vez, y para el pago de los impuestos federales, los Estados pueden establecer sus propios sistemas de créditos fiscales reembolsables. Dejando de lado los sistemas establecidos a nivel federal, en este punto se detallan las condiciones de las deducciones fiscales existentes en la provincia de Quebec.

La principal deducción fiscal quebequesa es la Prime pour l'Emploi o Work Bonus, orientada a los trabajadores/as de bajos salarios. Existe una modalidad básica, una modalidad "adaptada" y un suplemento. La modalidad adaptada se dirige a unidades familiares en las que hay una persona con discapacidad, mientras que la modalidad de suplemento se dirige, durante un periodo determinado, a personas que han accedido a un empleo tras percibir rentas de garantía de ingresos. Se trata en ese sentido de una fórmula específica de "estímulos al empleo", que ofrece una protección adicional, en el marco del sistema de créditos fiscales, en la transición de las rentas mínimas al empleo.

Para percibir la modalidad ordinaria, deben haberse percibido durante el año ingresos superiores a $\mathbf{2 . 4 0 0}$ dólares canadienses en el caso de una persona sola y 3.600 en el caso de una pareja. Los ingresos máximos para beneficiarse de la ayuda y las cuantías máximas para cada unidad familiar son las que se muestran en la Tabla 9.

Tabla 9. Cuantías y umbrales de acceso para el Work Premium en Quebec por composición familiar en 2018 (en dólares canadienses)

\begin{tabular}{|l|c|c|}
\hline Composición familiar & $\begin{array}{c}\text { Ingresos } \\
\text { máximos }\end{array}$ & Cuantía máxima \\
\hline Persona sola & $18.257,56$ & 768,36 \\
\hline Pareja sin hijos & $28.346,65$ & $1,199,06$ \\
\hline Familia monoparental & 35.096 & $2,452,20$ \\
\hline $\begin{array}{l}\text { Pareja con al menos un/a } \\
\text { hijo/a }\end{array}$ & $48.246,0$ & $3,189,00$ \\
\hline
\end{tabular}

Fuente: Elaboración propia.

La percepción de la prestación puede hacerse en un pago único o como adelanto mensual, si bien el adelanto solo puede ascender a entre el $50 \%$ y el $75 \%$ de la cuantía anual prevista, y siempre que esa cuantía supere un umbral determinado.

Cabe señalar, por otra parte, que Quebec cuenta con hasta 25 créditos fiscales reembolsables diferentes. Si bien los más importantes son los orientados a los trabajadores de bajos ingresos, existen créditos 
fiscales reembolsables para, entre otras, las siguientes situaciones:

- Gastos de atención infantil, con un tope de 5.000 dólares, que se amplía hasta los 13.000 en caso de discapacidad severa. La deducción cubre entre el $75 \%$ y el $26 \%$ de tales gastos, dependiendo de los ingresos de la persona contribuyente. La deducción se puede percibir de forma anticipada siempre que se cumplan determinadas condiciones.

- Mantenimiento a domicilio de personas mayores de 70 años (36\% de los gastos de atención y cuidados abonados a terceros, con un máximo de 19.500 dólares, lo que supone una deducción máxima de 6.825 dólares anuales). La deducción se puede percibir de forma anticipada siempre que se cumplan determinadas condiciones.

\section{El impacto de las deducciones fiscales reembolsables}

Como se ha señalado en el capítulo introductorio, en este apartado se realizará un breve repaso del impacto que las deducciones reembolsables descritas previamente han tenido en cuanto a la reducción de la pobreza y la mejora en las tasas de inclusión laboral de los trabajadores de bajos salarios, así como en relación con otras posibles mejoras inducidas por estas ayudas, en el ámbito de la salud o del rendimiento educativo de los niños/as pertenecientes a las familias beneficiarias. También se analizan algunas cuestiones relacionadas con las dificultades con las que se han encontrado estos sistemas desde el punto de vista de su administración y gestión, así como en cuanto a los niveles de cobertura de la población potencialmente demandante.

A la hora de interpretar estos resultados es necesario tener algunas cuestiones en cuenta:

- Por una parte, las evaluaciones realizadas analizan el impacto de las ayudas concedidas y no necesariamente el sistema de gestión que representan los créditos fiscales. Especialmente en lo que se refiere a la reducción de la pobreza, por tanto, cabe pensar que los efectos se deban a la existencia de un sistema de prestaciones orientado a las familias de bajos ingresos, generalmente condicionado a la inclusión laboral, y no necesariamente a la provisión de estas ayudas mediante el sistema fiscal.

- Otra de las cuestiones que es necesario tener en cuenta es la dificultad de extraer conclusiones generalizables de la evaluación de programas concretos: el nivel de éxito de estos programas depende de características muy específicas (cuantías, criterios de acceso, tasas de imposición, etc.) y sus éxitos o fracasos no se repetirán necesariamente si los programas se diseñan de otra forma o si se aplican en otros contextos sociales, económicos o laborales.
También es necesario tener en cuenta que, siendo al menos tres los objetivos generales de este tipo de créditos (reducción de la pobreza infantil y apoyo a las familias, incitación al empleo y redistribución hacia los trabajadores de bajos salarios), el signo de las evaluaciones dependerá del objetivo concreto analizado.

- Por último, es necesario destacar que la mayor parte de las evaluaciones se refieren únicamente a dos de las experiencias descritas, la británica y la norteamericana, que han sido evaluadas con mayor frecuencia, profundidad y rigor, siendo mucho más escasa y difícil de obtener la información relativa a los demás programas puestos en marcha.

\subsection{El impacto de los créditos fiscales sobre la pobreza y los bajos salarios}

¿Han reducido las deducciones reembolsables la incidencia y la intensidad de la pobreza en los países en los que se han aplicado? Probablemente, el programa más exitoso en lo que se refiere a la reducción de la pobreza sea el estadounidense, con una reducción general de las tasas de pobreza de entre el $10 \%$ y el $15 \%$, dependiendo de las evaluaciones que se tengan en cuenta. Existe en cualquier caso un consenso importante en cuanto a que el EITC norteamericano ha contribuido a la reducción de la pobreza tanto mediante el fomento de la inclusión laboral como mediante la complementación de los salarios de las familias de bajos ingresos, especialmente en el caso de las familias monoparentales y de las personas con baja cualificación. En un contexto determinado por el incremento del empleo de bajos salarios y la reducción en la capacidad adquisitiva del salario mínimo, se calcula que los complementos salariales derivados de los créditos fiscales reembolsables han elevado por encima del umbral de pobreza los ingresos de 9,4 millones de personas, de las que 4,9 millones eran menores de edad (Carr et al., 2013). Los estudios más recientes, realizados por el Servicio de Investigación del Congreso norteamericano (CrandallHollick y Hugues, 2018), indican que el porcentaje de población en situación de pobreza pasó en 2016 del 15,5\% al 14,0 \% para el conjunto de la población gracias al impacto de estas deducciones, lo que supone una reducción de la tasa de pobreza del $11 \%$. En el caso de las familias monoparentales, la caída es del $20 \%$, pasando del $30,2 \%$ al $24,1 \%$.

El EITC supone además una fuente de seguridad frente a la incertidumbre. En efecto, de acuerdo a Athreya, Reilly y Simpson (2014), resulta efectivo garantizando a las familias monoparentales un cierto nivel de seguridad sin introducir al mismo tiempo desincentivos al empleo: protege las mujeres a cargo de familias monoparentales con poca cualificación laboral frente a la inseguridad económica, incrementando su consumo y reduciendo la volatilidad de sus ingresos. La deducción norteamericana consigue ofrecer esos niveles de 
seguridad promoviendo, al mismo tiempo, el acceso al empleo de estas mujeres, al menos desde el punto de vista extensivo, y con reducciones muy moderadas desde el punto de vista intensivo. En parecido sentido, McGranahan (2016) ha demostrado que los créditos fiscales norteamericanos reducen la exposición de los hogares perceptores al endeudamiento, en la medida en que la prestación se utiliza para ponerse al día en relación con las deudas contraídas durante el ejercicio. El incremento en el consumo que se asocia a la percepción del EITC también provoca sin embargo un recurso mayor a los créditos al consumo y/o a la utilización de las tarjetas de crédito. El incremento del patrimonio que se produce es en todo caso superior a la deuda adquirida y se produce una mejora en las situaciones de privación material de estas familias.

En el caso británico, Gregg et al. (2012) apuntan a un cierto éxito en lo que se refiere a la reducción de las tasas de pobreza, con una relación clara entre el incremento en el gasto destinado a estas prestaciones, $\mathrm{y}$ al conjunto de las prestaciones familiares, y la reducción de las tasas de pobreza, especialmente entre la población infantil. Además, el impulso dado a partir de 2003 al sistema de tax credits resultó para estos autores vital a la hora contrarrestar el estancamiento en las remuneraciones laborales que se produjo en los primeros años de la década y las reducciones salariales asociadas a

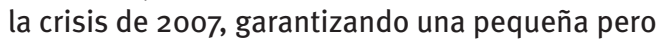
continua mejora en los niveles de ingresos de la población con menor renta.

Por el contrario, en el caso francés, el impacto de la Prime pour l'Emploi en cuanto a la reducción de la pobreza fue desde un inicio pequeño (Courtiuex, 2006). La tasa de pobreza general se reduce tras la aplicación de este crédito del 10,4\% al 10\%, de la población, lo que apenas supone un descenso del $4 \%$. Dada su escasa cuantía, su capacidad de aumentar la renta de las familias es sin duda reducida: de acuerdo con las microsimulaciones realizadas, si en el caso de la decila más pobre el conjunto de las ayudas públicas eleva los ingresos de las familias en un $109 \%$, la PPE apenas lo hace en un $1,5 \%$. Sin embargo, de acuerdo a este mismo autor, la prima para el empleo demostró ser una herramienta relativamente eficiente desde el punto de vista de la progresividad fiscal, en la medida en que contrarrestó el incremento de las desigualdades asociado a las reformas impositivas realizadas en Francia en los años precedentes.

Los resultados neozelandeses parecen más ambiguos. Las evaluaciones oficiales señalan que el $40 \%$ de los hogares con menores ingresos incrementaron su renta entre un $13 \%$ y un $17 \%$, mientras que los hogares con ingresos superiores a la media lo hacían en torno a un $8 \%$ (Dalgety et al., 2010). Otros autores plantean sin embargo resultados menos alentadores. Para St. John y Dale (2012), la valoración del sistema es básicamente negativa, debido al abismo que abre entre las familias con empleo y sin empleo, y debido también a la pérdida de eficiencia que implica su extensión a los niveles de renta medios e incluso altos. Otras evaluaciones independientes, como la realizada por el centro Nzier, coincide en la escasa selectividad del sistema -el $40 \%$ del gasto se destina a familias con ingresos medios y altos-, su reducida efectividad en lo que se refiere a la incitación laboral y su ineficiencia en lo que se refiere al objetivo de rentabilización del empleo (Nzier, 2011).

En lo que se refiere a la reciente experiencia italiana, previamente ya se ha señalado que la deducción fiscal introducida en 2014 reduce la tasa de pobreza en 0,6 puntos porcentuales y el índice de Gini en 0,25 (Astarita et al., 2016).

\subsection{Trampa de la pobreza, acceso al empleo y niveles salariales}

Desde el punto de vista de la promoción de la inclusión laboral, otro de los objetivos declarados de estas deducciones, hay un consenso claro al señalar que el EITC norteamericano - sin duda el más sometido a evaluaciones y análisis - ha generado un notable incremento de la inclusión laboral de sus destinarios (Marr, Charite y Huang, 2013). De acuerdo a Meyer (2010), la mejora de la inclusión laboral inducida por el EITC resultó especialmente elevada entre las mujeres solas con hijos/as a cargo y/o con bajos niveles de formación. De hecho, se calcula que por cada incremento de 1.000 dólares en la cuantía máxima del EITC se han obtenido incrementos en la tasa de actividad de las mujeres solas con hijos/as a cargo de entre el $20 \%$ y el $31 \%$ (Eamon et al., 2009).

Además, según estos autores, no existen evidencias de que las personas beneficiarias de estas prestaciones reduzcan su dedicación laboral cuando se pierde el derecho a la ayuda o cuando esta decrece de forma significativa. En ese sentido, no se han encontrado evidencias de que el diseño del EITC haya reducido el número de horas de trabajo de sus beneficiarios, tal y como teóricamente hubiera cabido esperar. En efecto, el diseño del EITC permite pensar, de acuerdo a los modelos teóricos imperantes en relación con la elasticidad de la oferta de mano de obra, que puede afectar al acceso al empleo desde el punto de vista extensivo (más personas desean acceder a un empleo), pero no desde el punto de vista intensivo (más personas desean trabajar más horas). Sin embargo, la evidencia empírica disponible no confirma tales previsiones, ya que, al menos en el caso de las familias monoparentales, se han producido mejoras desde el punto de vista extensivo, sin que desde el punto de vista intensivo la situación empeorara. En el caso de las familias biparentales, sí se ha producido una cierta, aunque limitada, reducción en el número de horas trabajadas (Eissa y Hoynes, 2008).

En una revisión más reciente de las investigaciones realizadas sobre la capacidad de promover el acceso 
al empleo del EITC, Nichols y Rothstein (2015) confirman que este sistema tiene efectos positivos en el acceso al empleo de las mujeres solas con cargas familiares, neutros e incluso negativos en el caso de las mujeres en hogares biparentales e insignificantes en el caso de los hombres. La revisión también confirma que el impacto del EITC en lo que se refiere al acceso al empleo es mayor en lo que se refiere a la intensidad del empleo que a su extensión (crece el número de personas que trabajan, pero no las horas de trabajo de quienes ya lo hacían), si bien también en este aspecto se ha demostrado un cierto impacto, en cualquier caso reducido. A parecidas conclusiones llega el Servicio de Investigación del Congreso norteamericano, cuyos análisis con relación a esta cuestión confirman el claro impacto positivo en lo que se refiere a la inclusión laboral de las mujeres a cargo de familias monoparentales y el más dudoso impacto en el caso de las familias biparentales, con un posible efecto desincentivado en el caso del acceso al empleo del segundo perceptor de ingresos de la familia (Crandall-Hollick y Hugues, 2018).

En el caso francés, el impacto de la Prime pour l'Emploi en cuanto al incremento de la disponibilidad laboral fue, incluso en tiempos de crecimiento económico, pequeño. De acuerdo a Courtiuex (2006), el incremento de la oferta de mano de obra fue de entre un $0,3 \%$ y un $0,8 \%$.

En lo que se refiere al Reino Unido, Gregg et al. (2012) apuntan a un "pequeño aunque directo impulso al empleo" como consecuencia del rediseño del Working Tax Credit en 2003. Una vez aislado el efecto de la positiva coyuntura económica durante los primeros años de aplicación, las evaluaciones realizadas identifican un cierto efecto positivo en términos de incitación al empleo, especialmente en lo que se refiere a las familias monoparentales, lo que redujo de forma sustancial el número de niños/as en hogares con todos sus adultos en paro. No parece por otra parte, de acuerdo a estos autores, que la introducción de estos créditos, al menos en el Reino Unido, haya impulsado los salarios más bajos a la baja, tal y como podría temerse, convirtiendo la prestación en una subvención de la que, en última instancia, se apropiarían las empresas.

Sin embargo, algunos estudios norteamericanos sí detectan un impacto negativo en los salarios de los trabajadores menos cualificados, como consecuencia precisamente del incremento en la oferta de mano de obra poco cualificada que provoca el EITC. Así, según Leigh (2010), por cada $10 \%$ de incremento en la cuantía del EITC el salario de las personas con estudios primarios se reduce un $5 \%$ y el de las personas con estudios secundarios un $2 \%$, no viéndose afectado el salario de las personas con estudios universitarios. En el mismo sentido, un incremento del $10 \%$ en el número de potenciales beneficiarios se traduce en una reducción de entre el $9 \%$ y $10 \%$ en el salario neto por hora trabajada para trabajadores con las mismas características socioprofesionales. Para este autor, el colectivo más perjudicado por este efecto es el de los trabajadores de baja cualificación y sin hijo/as, que no se ven beneficiados por la ayuda, pero experimentan su impacto negativo en cuanto a la reducción de los salarios.

Otro estudio (Rothstein, 2009) indica resultados parecidos: según este autor, la expansión del EITC a mediados de los años noventa, al incrementar la oferta de mano de obra, provocó un descenso de los salarios de los trabajadores con menor cualificación, que se compensó en cualquier caso debido al incremento de la demanda de este tipo de empleos. De esta forma, afirma el autor, los empresarios se beneficiaron de 0,72 centavos por cada dólar gastado en esta prestación: de ellos, o,30 derivarían de la reducción salarial directamente experimentada por las trabajadoras beneficiarias de estas ayudas y 0,43 de las pérdidas salariales de trabajadoras que no se benefician de estos créditos. El autor pone de manifiesto además una paradoja adicional: si se estableciera un sistema de impuesto negativo incondicional, que no requiriera una participación laboral mínima, los salarios de este colectivo se incrementarían, debido a la reducción de la oferta de empleo que traería aparejada la existencia de una prestación no condicionada al empleo, de forma que cada dólar destinado a esta prestación el ingreso de los trabajadores de bajos salarios se incrementaría en 1,39 dólares (Rothstein, 2009)9.

Apenas existen estudios de impacto con relación al efecto reductor de la pobreza de las deducciones fiscales españolas. Antes ya se ha señalado, en cualquier caso, que sus efectos redistributivos son escasos debido a su escasa focalización (se orienta a todas las madres que abonan al menos 100 euros mensuales en cotizaciones sociales). Con todo, algunos estudios (Azmat y González, 2010) han hallado un impacto importante de esta prestación sobre la fertilidad (casi un $5 \%$ ) y sobre la tasa de empleo de las mujeres potencialmente demandantes (en torno a un $2 \%$ ).

Además, a partir de las posibilidades que Euromod da para la microsimulación del impacto de reformas en el diseño de los sistemas fiscales y de prestaciones económicas, Ayala y Paniagua (2017) han evaluado el efecto que tendría la introducción de un complemento salarial para mujeres trabajadoras desde el punto de vista de la creación de empleo y la redistribución de la renta. El complemento salarial propuesto se inspira en el EITC norteamericano y se basa en la modificación de la deducción por maternidad española previamente descrita.

Las diferencias entre el sistema propuesto y el actual impuesto negativo español son importantes: por una parte, la nueva prestación se dirigiría a todas

9 Es importante destacar, en cualquier caso, que los trabajos de este autor se basan en modelos teóricos que simulan cambios en el comportamiento de los trabajadores y de los empresarios a partir de unas hipótesis previamente establecidas. 
las mujeres trabajadoras con salarios inferiores a un umbral determinado y no solo a las que tienen hijos/as menores de tres años. Por otra parte, la cuantía de la deducción se incrementa notablemente y se establecen tres tramos, en función del salario mensual: las mujeres con ingresos inferiores a 300 euros mensuales reciben 0,067 euros por cada euro de ingreso (de forma que la deducción crece a medida que crece el salario); las mujeres con salarios de entre 300 y 680 euros mensuales reciben una deducción fija de 320 euros; y las mujeres con ingresos de entre 680 y 1.000 euros reciben una deducción decreciente que equivale a la diferencia entre el tope máximo salarial (1.000 euros) y el salario percibido (una mujer con un salario de 900 euros percibiría una deducción de 100 euros, y una mujer con un salario de 999 percibiría 1 euro).

El interés del trabajo de Ayala y Paniagua radica en que su análisis tiene en cuenta los cambios que la introducción de un sistema de este tipo tendrían en la oferta de trabajo de las mujeres potencialmente beneficiarias, a partir de la aplicación de un modelo teórico determinado a las características sociodemográficas de las mujeres que conforman la muestra analizada. De esta forma, el impacto de la reforma se deriva del efecto combinado del cambio en las condiciones de la prestación (requisitos de acceso y cuantías) y del cambio inducido por la reforma en la oferta de trabajo de las mujeres potencialmente beneficiarias. El estudio no simula cambio alguno en el comportamiento laboral de los hombres.

Los resultados de esta reforma son aparentemente positivos: en lo que se refiere a la oferta de trabajo femenino, aplicando los parámetros del modelo teórico a las características de las mujeres de la muestra, Ayala y Paniagua estiman que el porcentaje de mujeres inactivas pasaría del $46 \%$ al $34 \%$, si bien, al mismo tiempo, las mujeres que trabajan a jornada completa pasarían del $39 \%$ al $31 \%$. En todo caso, para los autores la reforma sería muy eficaz desde el punto de vista extensivo (cuántas mujeres trabajan) y su impacto negativo desde el punto de vista intensivo (cuántas horas trabajan las mujeres ocupadas) sería reducido. Para materializarse, advierten, este efecto en la oferta femenina de empleo debería lógicamente acompañarse de un crecimiento paralelo en la demanda de puestos de trabajo para estas mujeres. Desde el punto de vista redistributivo, sumado el impacto en la oferta de trabajo al incremento de la remuneración de las mujeres beneficiarias, los efectos de la nueva deducción serían significativos: de acuerdo a las estimaciones de los autores, el índice de Gini se reduciría un $8 \%$, el ingreso del $10 \%$ de las mujeres con menores ingresos se incrementaría hasta un $60 \%$ y la tasa de pobreza se reduciría un $17 \%$. La reducción de la pobreza sería, además, especialmente importante en las familias con hijos/as

a cargo, lo que convertiría esta reforma en una herramienta eficaz de lucha contra la pobreza infantil.
4.3. Pobreza, salud, educación y bienestar en la infancia

La orientación hacia las familias $-\mathrm{y}$, por consiguiente, hacia la reducción de la pobreza infantil- es uno de los denominadores comunes de este tipo de herramientas fiscales, que a menudo exigen para su concesión, como se ha visto, la presencia de menores en el hogar. Las evaluaciones del sistema británico (Brewer y otros, 2009) ponen de manifiesto que este tipo de prestaciones pueden ser adecuadas en la medida en que mejoran las oportunidades laborales y los ingresos en las familias en situación o riesgo de pobreza, además de mejorar otros aspectos de su vida cotidiana, como su salud o autoestima.

El impacto del Earned Income Tax Credit norteamericano en la reducción de las tasas de pobreza infantil y en la mejora de la situación de los niños/as de los hogares que perciben esta deducción parece fuera de toda duda. Las evaluaciones del EITC norteamericano en lo que se refiere a la reducción de la pobreza infantil ponen de manifiesto que esta desgravación reduce la pobreza en la infancia en torno a un $25 \%$ (Nichols y Rothstein, 2015). En una de las revisiones más amplias y recientes del EITC, estos autores señala en ese sentido que millones de niños/a salen de la pobreza gracias a esta prestación y que su impacto positivo en términos de salud y educación tiene implicaciones significativas en lo que se refiere a la prevención de la transmisión intergeneracional de la pobreza. De acuerdo a Hoynes et al. (2015), el EITC y el CTC, en conjunto, hicieron que 4,8 millones de niños/as abandonaran la pobreza en 2015 .

Especialmente en el entorno norteamericano, se ha identificado además un muy notable impacto del sistema de créditos fiscales sobre la salud, la alimentación o el rendimiento escolar de la población infantil ${ }^{10}$ (Marr, 2015). Un estudio reciente (Averett y Wang, 2015) pone de manifiesto el carácter multidimensional de los impactos del EITC sobre el bienestar infantil, en la medida en que parece acreditado su efecto positivo en lo que se refiere a la salud, la calidad del entorno doméstico o las habilidades no cognitivas de los niños/as que residen en las familias que perciben la prestación, probablemente a través de la mejora de los ingresos familiares, los niveles inclusión laboral maternos y la mejora de su estado de salud física y mental.

Existe también una evidencia creciente con relación al impacto del EITC en la salud de las mujeres que lo perciben y de sus hijos/as. Así, de acuerdo a Hoynes et al. (2012), los hijos/as de las mujeres que se beneficiaron en mayor medida de la expansión del EITC registraron mejoras significativamente mayores

${ }^{10}$ Como se ha señalado previamente, tales efectos no se refieren necesariamente de forma específica al sistema de créditos fiscales, sino a cualquier sistema de garantía de ingresos mínimos orientado a las familias con hijos/as. 
en diversos indicadores de salud infantil (bajo peso al nacer, nacimientos prematuros, etc.). Además, las madres que en mayor medida se beneficiaron del EITC recibieron en mayor medida atención prenatal y mantuvieron conductas, en relación por ejemplo con el consumo de tabaco y alcohol, más saludables que el grupo de control. Más recientemente, Evans y Garthwaite (2014) demostraron que la expansión del EITC tuvo como consecuencia una mejora en el estado de salud física y mental de mujeres a cargo de familias numerosas. En sentido parecido, Hoynes, Miller y Simon (2015) demostraron que un incremento de mil dólares en la percepción de la prestación se asocia con un reducción de entre el 1,6\% y el 2,9\% en las tasas de bajo peso al nacer, con reducciones aún más elevadas entre los hijos/as de madres de origen afroamericano.

También se ha detectado un cierto impacto del EITC en la propensión a la nupcialidad en Norteamérica, de signo diferente en función de la situación socioeconómica de las parejas: en el caso de las parejas más pobres con un solo perceptor de ingresos, el diseño de la prestación promueve el matrimonio, mientras que en el caso de las familias con dos perceptores lo penaliza. La evidencia al respecto, así como sobre el efecto de esta prestación en la fecundidad, no es en cualquier caso concluyente (Nichols y Rothstein, 2015).

Por otro lado, también parece estar demostrado el impacto de estas prestaciones sobre el rendimiento educativo de los niños/as que las reciben y puede decirse que existen conclusiones robustas en la literatura sobre este positivo impacto, con consecuencias significativas a largo plazo sobre diversos indicadores de bienestar en la edad adulta (Nichols y Rothstein, 2015). Dahl y Lochner (2009), a partir de una muestra de más de 5.000 niños/as, hallaron que un incremento de 1.000 dólares en la prestación recibida por cada familia incrementaba en un $6 \%$ los resultados en matemática y lectura, produciéndose las mejoras más importantes en los grupos menos favorecidos y en los niños/as de menor edad. Se trata, señalan los autores, de un efecto modesto aunque esperanzador. En el mismo sentido, a partir de una revisión de los estudios realizados en este ámbito, Duncan et al. (2011) han estimado que por cada 3.000 euros adicionales de ingresos recibidos por la familia durante los primeros años del ciclo educativo, la mejora en el rendimiento escolar equivale a dos meses adicionales de escolarización. Además de incidir en los resultados académicos, la percepción del EITC también parece afectar a la continuidad de los estudios. En ese sentido, se ha demostrado que un incremento en la cuantía máxima del EITC se asocia con incrementos en los niveles de escolarización a la edad de 19 años (Maxfield, 2013). En el mismo sentido, se ha demostrado que un incremento de la cuantía percibida de 100 euros se asocia con un incremento de la matriculación en el último curso de educación secundaria de 0,3 puntos porcentuales (Manoli y Turner, 2018).
El impacto positivo de este programa se asocia también en mejoras en el desarrollo infantil cuando se analiza mediante técnicas longitudinales. Según Hamad y Rehkopf (2016), la percepción de la prestación se relaciona con una reducción en la prevalencia de trastornos conductuales en la población juvenil, con una reducción de entre el $2 \%$ y el $5 \%$ por cada incremento de mil dólares en las cantidades percibidas. Los autores señalan que estas mejoras pueden estar relacionadas con la mejora en el estado de salud física y mental de las madres puesta de manifiesto por otros estudios y que se mantienen, al menos en parte, en el medio y largo plazo.

\subsection{Acceso a las deducciones, problemas administrativos y experiencia de las personas usuarias}

La normalización, simplificación y “legibilidad” que se atribuye al sistema de créditos fiscales no impide, en cualquier caso, la emergencia de problemas importantes relacionados con su administración y gestión. Efectivamente, si bien es cierto que la integración del sistema fiscal y de protección social que implica el desarrollo de los créditos fiscales ha buscado, entre otros objetivos, simplificar y hacer más accesible el conjunto del sistema, los resultados en ese aspecto no parecen haber sido completamente satisfactorios, con dificultades tanto para la gestión de los pagos como para garantizar que accede a ellos el conjunto de la población potencialmente demandante. Del mismo modo, se han puesto de manifiesto dificultades importantes, a la hora de plantear esa integración, entre el carácter crecientemente individualizado del sistema fiscal y la naturaleza familiar de las prestaciones asistenciales (Mirrlees et al., 2012).

En lo que se refiere a los problemas administrativos, los principales se derivan del carácter anual de las declaraciones fiscales y del carácter mensual (e incluso semanal, en algunos países) de la mayor parte de las prestaciones, así como de las dificultades para adaptarse a los cambios constantes en las circunstancias personales y familiares -composición familiar, volumen de ingresos, horas de trabajo, etc. - que determinan el acceso a los créditos. En el caso británico, los errores se derivan fundamentalmente del hecho de que la ayuda se concede a partir de los ingresos del año anterior, compensándose al final del año los desajustes que por exceso o por defecto se pueden haber producido. Este sistema provoca numerosos errores: en $\mathbf{2 0 0 7}$ el $14 \%$ de los pagos tuvieron que ser compensados al alza al finalizar el año, mientras que un $29 \%$ se debieron corregir a la baja (Millar, 2008). La demanda de devoluciones asociadas a los cobros indebidos dio lugar a una cierta sensación de insatisfacción en relación al conjunto del sistema de créditos fiscales. Algunos cambios introducidos en 2006 mejoraron en parte la situación, aunque complicaron la gestión administrativa del sistema. El 
sistema fiscal británico, señalan los expertos, no está suficientemente capacitado para gestionar pagos que se deben ajustar a cambios frecuentes y diversos en las circunstancias personales de los contribuyentes (Mirrlees et al., 2012). Dicho esto, matizan los expertos, las tecnologías avanzan con rapidez y las mejoras en la posibilidad de transferir información en tiempo real deberían abrir nuevas posibilidades en este campo.

En lo que se refiere a la cobertura de los créditos fiscales con relación a la demanda potencial, los resultados son insatisfactorios, especialmente en el Reino Unido. En Estados Unidos, por el contrario, se calcula que acceden a estos créditos entre el $70 \%$ y el $80 \%$ de los potenciales beneficiarios, abonándose en torno al $86 \%$ de los fondos que se deberían abonar en caso de que el $100 \%$ de las personas potencialmente demandantes ejercieran su derecho a solicitar la deducción (Holt, 2011). Algunos estudios también han mostrado, en cualquier caso, que el acceso a estas deducciones es mayor en la fase de incremento (phase in) que en la fase de decremento (phase out) de la deducción y que existen diferencias importantes en función de los grupos sociodemográficos, con tasas de acceso más elevadas entre las mujeres (en torno al $80 \%$ ) que entre los hombres, con tasas de acceso cercanas al $75 \%$ (Nichols y Rostein, 2015).

En el caso del Reino Unido se calcula que la tasa de utilización del Child Tax Credit en relación a la población potencialmente demandante es del $83 \%$, mientras que en el caso del Working Tax Credit se reduce al $63 \%$. Se calcula que en el caso del CTC el gasto realizado equivale al $94 \%$ del gasto máximo en caso de plena utilización de la prestación, mientras que en el caso del WTC se hizo uso del $86 \%$ de los fondos teóricamente disponibles (HM Revenue and Customs, 2012). El desconocimiento no es, en cualquier caso, la principal razón que explica la no utilización de estos créditos: de acuerdo a Breese et al. (2011), el $84 \%$ de las personas que no hicieron uso de sus derechos en este aspecto conocían la existencia de los créditos, si bien pensaban, en un $78 \%$ de los casos, que dadas sus circunstancias personales no tenían derecho a ellos. Entre quienes no los solicitaron por otras razones, destacan quienes no lo hacen por no querer depender de las ayudas públicas, quienes consideran los trámites demasiado complicados, quienes temen tener que devolver después una parte del dinero o quienes consideran que, dada la cuantía a la que tienen acceso, no merece la pena realizar los trámites.

Por otro lado, no deben dejar de considerarse los problemas de gestión que se derivan de la doble naturaleza de estas prestaciones (deducciones fiscales y, al mismo tiempo, prestaciones netas). De acuerdo a Crandall-Hollick y Hugues (2018), la incidencia de errores y cobros indebidos es alta en la gestión de la prestación, debido entre otras razones a que se trata de una prestación derivada de una autodeclaración de ingresos. La reducción de ingresos fiscales derivada de estos errores no es sin embargo, de acuerdo a estos autores, significativa: de acuerdo a los datos oficiales de la administración norteamericana, la pérdida de ingresos fiscales derivada de los errores de administración del EITC supone un $6 \%$ del conjunto de las cantidades indebidamente no recaudadas. La no recaudación debido a la infradeclaración de ingresos profesionales representa por el contrario el 51,9\% de toda la pérdida de recaudación detectada.

De hecho, de acuerdo a un reciente estudio de Jones y Ziliak (2019), la constatación de los errores administrativos y de la elevada tasa de no recurso (non take up) a estas deducciones debería hacer reconsiderar su impacto sobre la reducción de la pobreza. Para estos autores, los datos que habitualmente se manejan sobre la capacidad redistributiva del EITC se derivan en general de simulaciones realizadas a partir de encuestas, en las que se presupone el acceso a las deducciones de toda la población potencialmente beneficiaria. Sin embargo, cuando se analiza el acceso real al sistema, se observa que el número de personas que salen de la pobreza gracias a este sistema está sobreestimado en cerca de un $33 \%$. El estudio de Jones y Zillak también pone de manifiesto que los problemas del EITC tienen más que ver con el no acceso a la deducción de personas potencialmente elegibles que con su reverso, es decir, el cobro de la deducción por parte de personas que no tendrían derecho a ella $\mathrm{y} / \mathrm{o}$ en cantidades superiores a las que realmente les corresponderían.

En Europa, el impacto sobre el funcionamiento del sistema de los errores y cobros indebidos fue uno de los principales motivos del fracaso de la experiencia británica. En ese sentido, para Clegg (2015), los problemas administrativos demostraron pronto ser el talón de Aquiles del modelo de créditos fiscales, hasta el punto de que la administración de estas deducciones se convirtió en un verdadero fiasco político. El principal problema administrativo - como en el caso de las prestaciones directas, cabe recordar- se originaba por los frecuentes cambios en las circunstancias personales y profesionales de las personas beneficiarias, que no se tuvieron suficientemente en cuenta a la hora de diseñar el sistema de deducciones. Todo ello provocó, como explica Clegg, innumerables polémicas con relación a la generación de cobros indebidos y a las fórmulas utilizadas para su recuperación por parte de la administración, con continuas criticas al enfoque punitivo adoptado por el Departamento de Hacienda.

En todo caso, la mayor normalización del sistema fiscal en relación con el sistema de prestaciones sociales ha sido también una de las razones aducidas para justificar el recurso a los créditos fiscales. Aunque tal cuestión no ha sido investigada en profundidad, puede pensarse que la población, efectivamente, considera menos estigmatizante el acceso a estos créditos en comparación con las prestaciones convencionales de garantía de ingresos: 
en efecto, un estudio británico señala que, mientras que un $66 \%$ de la población beneficiaria reconoce que existe un cierto estigma en lo que se refiere a la solicitud de prestaciones económicas asistenciales, en el caso de los créditos fiscales el porcentaje se reduce al $25 \%$. El $75 \%$ de las personas encuestadas señalaba además que existían diferencias entre ambas prestaciones en la medida en que los créditos recompensan la inclusión laboral (Breese, 2011).

\subsection{Efectos sobre la progresividad del sistema fiscal y la capacidad redistributiva del sistema de prestaciones e impuestos}

Uno de los principales efectos de las deducciones fiscales reembolsables, en el contexto de fiscalización de las políticas sociales al que antes se ha hecho referencia, tiene que ver con la mejora de la progresividad fiscal y de la capacidad redistributiva del conjunto del sistema de prestaciones e impuestos. Esta capacidad se relaciona claramente con la tensión entre las dos lógicas - reducción de impuestos versus redistribución- al que antes se ha hecho referencia.

En ese sentido, un reciente artículo de Avram (2018) analiza el efecto redistributivo de las deducciones fiscales y las desgravaciones o reducciones de la base imponible desarrolladas en seis países de Europa. De acuerdo a su análisis, las desgravaciones o reducciones en la base son por lo general regresivas, mientras que las deducciones en la cuota son neutrales o moderadamente progresivas. En todo caso, advierte la autora, el impacto de estas herramientas desde el punto de vista redistributivo es poco claro y difícil de prever, en la medida en que está estrechamente relacionado con el resto de las características del sistema impositivo (tipos, posibilidades de declaración conjunta e individual, bases exentas, etc.), lo que desaconseja su utilización como herramienta redistributiva.

Avram destaca sin embargo que la naturaleza reembolsable de algunas de estas deducciones supone un cambio radical en su capacidad redistributiva. Para esta autora, "ni las desgravaciones ni las deducciones son herramientas particularmente efectivas desde el punto de vista redistributivo. Sin embargo, hay una excepción: los créditos fiscales reembolsables dirigidos a hogares de bajos ingresos. Si bien la muestra utilizada en este análisis contiene muy pocos ejemplos de tales instrumentos para justificar una conclusión sólida, encontramos que los créditos fiscales reembolsables son fuertemente progresivos, independientemente del entorno en el que operen".

En el mismo sentido, Batchelder, Goldberg y Orszag (2006) han defendido la necesidad de que todas las deducciones fiscales tengan carácter reembolsable. Para estos autores, la naturaleza reembolsable de estas deducciones resulta más efectiva a la hora de alcanzar los objetivos de las deducciones fiscales convencionales y resultan más eficaces desde el punto de vista económico, en la medida en que suavizan las fluctuaciones macroeconómicas. Desde ese punto de vista, Batchelder, Goldberg y Orszag defienden el carácter reembolsable de las deducciones no tanto desde la óptica de la redistribución o de la progresividad, sino desde la óptica de la eficiencia en el diseño del sistema fiscal.

Para McCabe (2018), el carácter reembolsable de estas prestaciones permite superar las dos lógicas principales que subyacen a las políticas de apoyo a las familias -la lógica de la reducción de impuestos a las familias con hijos/as con obligaciones tributarias derivadas de su nivel de renta y la lógica del apoyo económico selectivo a las familias pobres sin ingresos- a favor de una tercera lógica, orientada a la complementación de ingresos de todas las familias con hijos/as. Si las dos primeras lógicas diferencian a las familias pobres de las familias trabajadoras de ingresos modestos, la tercera de ellas supera esa distinción y apuesta por mecanismos orientados al conjunto de las familias, moduladas en función del tamaño familiar y no tanto en función de la deuda tributaria o la posición en el mercado de trabajo.

\section{Conclusiones: ventajas y desventajas de las deducciones fiscales reembolsables y de su posible aplicación en Euskadi}

A partir del análisis del funcionamiento e impacto de las deducciones fiscales reembolsables, en este último apartado se analizan las razones que explican su relativamente amplio desarrollo, así como las ventajas que plantean de cara al rediseño del conjunto de los sistemas de protección social. Junto a esas ventajas, se señalan también los inconvenientes que pueden presentar o, desde otro punto de vista, las razones que explican su fracaso en países como Francia o Reino Unido. Finalmente, se plantean algunas reflexiones sobre el potencial de este tipo de herramientas en el marco de la Comunidad Autónoma del País Vasco.

\subsection{Las razones que explican el "éxito" de las deducciones fiscales reembolsables}

El análisis de la literatura relativa al funcionamiento y el impacto de estas deducciones permite identificar cuáles son las razones que explican su desarrollo y cuáles son las ventajas que tienen, frente a los enfoques convencionales, de cara a la reorientación de los sistemas de protección social.

En primer lugar, puede decirse que el uso de estas herramientas incrementa la progresividad del sistema fiscal y permite extender a toda la ciudadanía unos beneficios fiscales de los que hoy sólo se beneficia una parte de la ciudadanía ${ }^{11}$. Los

\footnotetext{
${ }^{11}$ No se trata de una cuestión irrelevante: en el caso de Gipuzkoa,
} 
créditos fiscales reembolsables, como señala Avraam (2018), son claramente progresivos. El recurso a estas herramientas permite además sustituir la lógica de la reducción de la presión fiscal por la lógica de la redistribución hacia las familias de menor renta: en efecto, las deducciones fiscales convencionales se relacionan claramente con las promesas de reducción de la carga fiscal "a los que menos tienen" que preconizan la mayor parte de los partidos políticos. Parece claro, sin embargo, que esta estrategia de reducción de la carga fiscal a las familias con menos ingresos tiene un recorrido corto, en la medida en que su deuda tributaria es reducida, y el margen para una reducción adicional es pequeño. Introducir el concepto de reembolsabilidad, sin embargo, permitiría pasar de la idea de la reducción de impuestos a la idea de la redistribución, mediante el acceso de toda la ciudadanía a unas prestaciones que las familias con renta suficiente ya perciben a través de la reducción de sus responsabilidades tributarias.

Otra de las ventajas que plantean estas herramientas -especialmente cuando se orientan a los trabajadores/as de bajos salarios- es la de superar la lógica de la sustitución de ingresos por una lógica de complementación de estos. En efecto, las prestaciones de garantía de ingresos convencionales están diseñadas para "sustituir" un ingreso que ha desaparecido (es el caso de la mayor parte de las pensiones, subsidios por desempleo, etc.). El incremento de la precariedad laboral y el empleo de bajos salarios han obligado sin embargo a introducir una lógica de complementación en virtud de la cual las prestaciones públicas, en lugar de sustituir la renta que deja de percibirse, complementan los ingresos (escasos) que se perciben. Se trata, en cualquier caso, de un cambio de lógica que ya incorporan buena parte de los sistemas de garantía de ingresos mediante la introducción de diversos mecanismos de estímulos al empleo y que no se

extensible a los demás territorios de la Comunidad Autónoma del País Vasco, tomando como referencia a una familia con tres hijos/as menores de seis años, y sin contar otras posibles deducciones, las unidades familiares con ingresos superiores a 30.000 euros se benefician de una deducción fiscal por descendientes de 3.537 euros. Las familias con ingresos inferiores no se benefician sin embargo plenamente de esa deducción, ya que la cuota tributaria que generan es inferior a la deducción: en el caso de las familias con ingresos de 20.000 euros, por ejemplo, la deducción que efectivamente reciben es de 1.550 euros, ya que su cuota tributaria es esa; el resto de la deducción (2.000 euros) no puede ser aprovechada por esos contribuyentes. En el mismo sentido, los contribuyentes con ingresos inferiores a 12.000 euros no reciben un solo euro por esta vía, ya que no generan, debido a sus escasos ingresos, deuda tributaria alguna. Si bien las diferencias son menos marcadas en las unidades con uno/a o dos hijos/as, el carácter regresivo de este sistema parece claro. En términos agregados, en 2013 , solo el $40 \%$ de los contribuyentes con bases liquidables inferiores a 10.000 euros pudieron aplicarse esta deducción, y solo se beneficiaron del $21 \%$ del importe de las deducciones a las que teóricamente hubieran tenido derecho. De media, cada uno de estos contribuyentes dejó de beneficiarse de una deducción de casi 1.400 euros. Los contribuyentes con ingresos de entre 10.000 y 20.000 euros se beneficiaron del $91 \%$ del importe de esas deducciones, beneficiándose el resto de los contribuyentes del 100\% de la deducción. Las unidades familiares que no realizaron la declaración por IRPF, lógicamente, no se beneficiaron en modo alguno de esta deducción. asocia necesariamente por tanto a la vía de la fiscalidad $^{12}$.

Una de las principales razones que explica el desarrollo de estas herramientas y, en principio, una de sus mayores ventajas, es que favorecen la normalización de los sistemas de garantía de ingresos y la simplificación de su funcionamiento, reduciendo además la estigmatización asociada a la percepción de prestaciones selectivas y condicionales de garantía de ingresos. En ese sentido, parece fuera de toda duda que percibir una prestación económica desde un dispositivo, el fiscal, al que accede toda la población puede ser más normalizador y menos estigmatizante que hacerlo desde dispositivos selectivos y condicionales, sometidos además a un escrutinio político y social constante.

De hecho, una de las principales razones que explican el desarrollo de estos sistemas ha radicado precisamente en su carácter "sigiloso" o "discreto" (Clegg, 2015), en la medida en que han conseguido "camuflar" un dispositivo de garantía de ingresos de carácter redistributivo - eso sí, orientado a los pobres que trabajan y no a los pobres que no trabajan- en un marco no asociado a la asistencia social tradicional: sacar a los trabajadores pobres del sistema asistencial de garantía de ingresos ha sido desde ese punto de vista uno de los objetivos de estas herramientas y una de las razones que explican su desarrollo en los países anglosajones. La razón era doble: por una parte, daba a los beneficiarios de estas deducciones un estatus diferente del que se daba a los perceptores de las prestaciones convencionales, reservadas a las personas inactivas. Por otra parte, permitía una extensión de los programas de apoyo a los trabajadores pobres difícil de alcanzar desde las prestaciones convencionales, dado el rechazo que despertaban en ciertos sectores políticos, mediáticos y sociales. Para Clegg, en relación con el caso británico, los laboristas siempre pensaron que la redistribución hacia la población

${ }^{12}$ Como se ha señalado en otros trabajos (Zalakain, 2014 y 2006), tras el carácter subsidiario y diferencial de las prestaciones de garantía de ingresos subyace una consideración de las personas beneficiarias como carentes de todo ingreso propio, lo que simplifica tanto conceptual como administrativamente la gestión de la prestación de ingresos mínimos. La extensión de las situaciones de precariedad laboral y la emergencia del fenómeno de los trabajadores pobres ha ido sin embargo abriendo el acceso a estas prestaciones a personas vinculadas al empleo y que perciben, con mayor o menor regularidad, ingresos salariales propios, con lo que la prestación asistencial pasa a tener un carácter eminentemente complementario. Ello implica cambios tanto de tipo administrativo - con dificultades relativas a la gestión- como conceptuales, que afectan de forma determinante a la función de las prestaciones de garantía de ingresos en un contexto de precarización laboral. Desde el punto de vista administrativo, la inadaptación viene marcada por las dificultades para tener en cuenta los frecuentes cambios en los ingresos y en la situación personal de las personas que tienen una vinculación a menudo desigual e intermitente con el mercado de trabajo, con frecuentes pagos indebidos, reclamación de devoluciones, etc. Desde el punto de vista conceptual, en la medida en que estas personas pueden no presentar problemas de exclusión social y precisar, únicamente, un cierto nivel de protección económica debido precisa mente a la insuficiencia de los salarios que reciben, su presencia en un dispositivo orientado a la inserción social resulta un tanto forzada. 
pobre sería más fácil y permanentemente aceptada si se orientaba a los trabajadores pobres y se articulaba a través del sistema fiscal.

También cabe destacar que una de las consecuencias de ese cambio ha sido, lógicamente, la reducción del número y el gasto asociado a las prestaciones asistenciales, derivando a una parte de las personas beneficiarias a otro dispositivo, el fiscal, y sin dejar por tanto de prestarles apoyo económico. En ciertos contextos socioeconómicos, aligerar - aunque sea de esta forma- la nómina de perceptores de prestaciones asistenciales y el gasto asociado a ellas puede resultar una estrategia conveniente.

Esta capacidad de camuflaje explica también, desde otro punto de vista, el éxito de las deducciones fiscales. Al considerarse en términos de contabilidad pública como ingresos no recaudados -y no como gasto efectivamente realizado-, el recurso a las deducciones fiscales resultó particularmente útil a los partidos políticos comprometidos en la reducción del gasto público en políticas sociales (McCabe, 2018). Su eficacia en términos de reducción del déficit público es en cualquier caso nula pues, aunque no se contabilice como gasto, el uso de estas prestaciones sí implica una reducción de la capacidad de recaudación que tiene un efecto claro en las cuentas públicas.

También cabe pensar que la gestión de ciertas prestaciones desde el sistema fiscal $-\mathrm{y}$ no desde los sistemas de servicios sociales o incluso de empleofavorece los avances hacia modelos de garantía de ingresos menos condicionales, definidos únicamente por criterios de necesidad económica y no por criterios de conducta o merecimiento moral. Si bien es cierto que ese cambio no requiere necesariamente de la gestión fiscal, parece claro que la tramitación de estas ayudas por parte de un sistema "aséptico" -que solo valora si se cumplen las condiciones económicas de acceso a la deducción-implica una separación más clara entre el derecho a la percepción de un apoyo económico en caso de necesidad y el derecho a la percepción de apoyos para la inclusión sociolaboral, que a menudo se asocia, de forma más o menos clara, a enfoques de carácter contraprestacional.

Otra de las ventajas que cabe atribuir a estos procesos de integración sociofiscal -muy particularmente en el caso de Euskadi- es la de evitar la creación de sistemas prestacionales paralelos para la cobertura de necesidades similares, que en ocasiones únicamente se diferencian por el nivel de renta de sus beneficiarios. Cabe a este respecto señalar dos ejemplos:

- Dejando al margen el sistema autonómico de prestaciones por hijo/a a cargo (cuya extensión y alcance es aún muy reducida), el apoyo económico a las familias vascas con hijos/as se realiza en la actualidad por dos vías: como hemos señalado anteriormente, las familias con ingresos superiores a un cierto umbral se benefician (a menudo sin saberlo) de las deducciones fiscales convencionales, mientras que las familias con ingresos inferiores a un umbral determinado se benefician de las prestaciones de garantía de ingresos ${ }^{13}$. Probablemente quede además un sector intermedio que no se beneficia, al menos plenamente, de ninguno de los dos sistemas.

- Algo parecido ocurre en el ámbito de la vivienda: una parte importante de la población con gastos de vivienda se beneficia de las deducciones fiscales por compra o alquiler, mientras que otra parte (más reducida y con menos recursos) recurre a la Prestación Complementaria de Vivienda, gestionada además hasta hace poco en el marco del sistema vasco de garantía de ingresos.

En ambos casos, sería factible un diseño más eficiente de estas prestaciones que permita atender desde un solo dispositivo a toda la población potencialmente beneficiaria, manteniendo en cualquier caso si es necesario dispositivos específicos para los colectivos con mayores necesidades. Este cambio tendría efectos desde el punto de vista de la normalización del acceso a estas prestaciones y, también, desde el punto de vista de su legitimidad social, ya que al ubicarse en un marco universal estarían menos expuestas al cuestionamiento político y social al que en general están expuestas las prestaciones asistenciales. En ese sentido, podría pensarse que una de las principales ventajas del recurso a las deducciones fiscales reembolsables podría ser la de "universalizar" las prestaciones de carácter selectivo, sin necesidad de recortar su cuantía y/o de incrementar extraordinariamente el gasto total que se viene realizando, en la medida en que las prestaciones selectivas se fusionan con un sistema de beneficios fiscales que ya existe y del que, por otra parte, sus beneficiarios son escasamente conscientes.

\subsection{Las razones que explican el "fracaso" de las deducciones fiscales reembolsables}

Frente a estos argumentos, no puede dejar de señalarse que dos de las principales experiencias recogidas en este informe - la francesa y la británica- están siendo, o han sido ya, desmanteladas. Junto a las ventajas señaladas en el punto anterior (que podrían en parte explicar su éxito), es también por tanto necesario explicar las desventajas, contraindicaciones o inconvenientes de este tipo de herramientas, algunas de las cuales explican su fracaso en estos países.

\footnotetext{
${ }_{13}$ Se trata, de acuerdo al Plan Vasco de Apoyo a las Familias actualmente vigente, de "un modelo atípico en Europa, de carácter selectivo y en cierto modo dual, en el que las familias de rentas medias y altas se benefician de desgravaciones fiscales y de una presión fiscal baja, y las de rentas bajas, o sin ingresos, del sistema de rentas mínimas, abierto a toda la población pero estrictamente condicionado a la percepción de unos ingresos máximos".
} 
La primera de las dificultades, y probablemente la principal, se relaciona con la dificultad para conciliar la lógica propia de los sistemas fiscales con la lógica de las prestaciones económicas convencionales, en lo que se refiere por ejemplo a la periodicidad en el cobro de la prestación (el sistema fiscal tiende a ciclos anuales y el de protección social a ciclos mensuales), el sujeto que genera el derecho a la prestación (el sistema fiscal es crecientemente individual, con posibilidades optativas de tributación conjunta, mientras que el prestacional se asocia a la unidad familiar o incluso al domicilio de residencia), las condiciones y requisitos de acceso, la información requerida, etc. Se trata de lógicas diferentes que, a menudo, han resultado difíciles de conjugar. En ese contexto, llegar a las personas que no están obligadas a realizar la declaración por IRPF y facilitar a la administración fiscal la información sobre sus circunstancias personales y profesionales es una dificultad que no debe subestimarse a la hora de plantear una posible aplicación de las deducciones fiscales reembolsables.

En ese sentido, debe insistirse en que, en la mayor parte de los casos, los sistemas de deducciones fiscales reembolsables no han sido capaces de evitar los problemas de non take up o de cobros indebidos que caracterizan a los sistemas tradicionales de garantía de ingresos. Este problema se agrava como ocurre también en cualquier caso en el caso de las prestaciones directas-cuando las condiciones de acceso a la deducción dependen de elementos muy variables, como puede ser la percepción de ingresos salariales intermitentes y discontinuos.

En un sentido parecido, también debe recordarse que las deducciones fiscales reembolsables no operan en abstracto, sino que interactúan con el resto de los elementos que definen el Impuesto sobre la Renta de las Personas Físicas - mínimos exentos, reducciones de la base, tramos y tipos nominales, otras deducciones, normas de tributación conjunta, retenciones, obligación de tributar, etc.- y también con el diseño de las cotizaciones a la Seguridad Social. Esta interdependencia puede contribuir no solo a oscurecer el diseño y el funcionamiento de las deducciones fiscales - frente al objetivo de legibilidad y simplificación antes señalado-, sino que puede neutralizar sus efectos o incluso revertirlos si se introducen otros cambios - por ejemplo, en los tipos y tramos del impuesto- que vayan en sentido contrario.

También cabe pensar -como una de las principales desventajas de este tipo de sistemas- en su contribución a la diferenciación entre dos grupos de perceptores de prestaciones: por una parte, quienes acceden al sistema de deducciones fiscales reembolsables (generalmente, familias con hijos/as $\mathrm{y} / \mathrm{o}$ vinculadas al mercado laboral), que acceden a un sistema normalizado y, en cierto modo, "respetable". Por otro lado, quienes se mantienen en el sistema convencional de garantía de ingresos, sin vinculación laboral, y crecientemente estigmatizado en la medida en que los grupos más cercanos a la inclusión social han sido derivados al sistema fiscal.

En todo caso, la mayor desventaja que plantea el recurso a las deducciones fiscales reembolsables se deriva de la propia esencia del sistema fiscal: en efecto, buena parte de los expertos en fiscalidad consideran que el sistema tributario debe responsabilizarse de la recaudación y que las políticas redistributivas deben hacerse mediante el gasto público. De alguna forma, la fiscalización de las políticas sociales que se ha analizado en este artículo cuestiona este principio, y atribuye a un mismo dispositivo la responsabilidad de recaudar y, al mismo tiempo, gastar. El mayor inconveniente de este modelo es que la asignación de determinados recursos económicos a determinados fines sociales se realiza desde el momento mismo de la recaudación, reduciéndose la capacidad de los decisores públicos para asignar unos presupuestos determinados a unas políticas determinadas y "capturando" de antemano un porcentaje determinado de la recaudación. Si bien eso ya está ocurriendo con el actual modelo de "bienestar oculto", una mayor integración de las políticas fiscales y sociales podría tener como consecuencia una reducción en la capacidad de asignación de recursos de quienes están al frente de las administraciones a las diferentes políticas públicas.

En el marco concreto de la Comunidad Autónoma del País Vasco, además, la introducción de este tipo de modelos redundaría en una reducción general de la recaudación que afectaría, en función de su porcentaje de participación en la asignación de la recaudación, a todos los niveles de la Administración, independientemente de que tuvieran o no competencias (y responsabilidades de gasto, por tanto) sobre las materias que generan el derecho a esas deducciones reembolsables.

\subsection{El potencial de los créditos fiscales en la Comunidad Autónoma del País Vasco}

Pese a estos inconvenientes, puede pensarse que las deducciones fiscales reembolsables podrían contribuir a mejorar el diseño de las políticas sociales en Euskadi. Aunque no puede decirse que estos sistemas hayan recibido hasta ahora una gran atención en la Comunidad Autónoma del País Vasco ${ }^{14}$, los tres territorios históricos vascos cuentan con un amplio margen de autonomía en lo que se refiere a la determinación del impuesto sobre las rentas de las personas físicas, lo que haría legalmente posible la introducción de medidas de este tipo en Euskadi,

${ }^{14} \mathrm{~A}$ ese respecto cabe señalar, en cualquier caso, que este tipo de deducciones han sido incluidas en los programas electorales para las elecciones forales por parte de algunos partidos vascos y que el Plan Vasco de Familia e Infancia, actualmente vigente, recoge entre sus medidas la "creación de un Grupo de Trabajo Interinstitucional, en el marco del Órgano de Coordinación Tributaria, para analizar las posibilidades de gestionar de forma integrada las prestaciones por hijo/a a cargo y las deducciones fiscales por descendientes". 
siempre que existiera el consenso político y social necesario para ello. Pero, a partir de la reflexión realizada en las páginas precedentes, ¿cuál es el potencial de los créditos fiscales en la Comunidad Autónoma del País Vasco? ¿En qué medida, o para qué necesidades, podría tener sentido el desarrollo en Euskadi de este tipo de herramientas?

Teniendo en cuenta tanto las ventajas como las desventajas señaladas anteriormente, puede pensarse que este tipo de herramientas podrían jugar un papel relevante en Euskadi al menos en tres ámbitos específicos:

- Las políticas de apoyo a las familias con hijos/as, tal y como se establece en el Plan Vasco de Familia e Infancia, mediante una reorientación del conjunto de las deducciones fiscales por descendientes y las prestaciones por hijos/a a cargo, en la línea del sistema actualmente existente en Alemania. La redefinición a partir de estas bases del sistema vasco de apoyo a las familias con hijos/as permitiría avanzar de forma efectiva en el Pacto Vasco por las Familias y por la Infancia, suscrito por todas las Administraciones vascas, avanzar en el paradigma de la inversión social y equiparar el gasto vasco en políticas de familia e infancia al que realizan la mayor parte de los países de la Unión Europea. Además de incrementar la eficiencia del sistema, el desarrollo de este tipo de políticas podría tener un cierto impacto, de acuerdo a la literatura revisada en este artículo, en lo que se refiere a las tasas fecundidad y de pobreza infantil, y podría contribuir a reducir la transmisión intergeneracional de la desigualdad.

- Las prestaciones de acceso a la vivienda en compra y alquiler, diseñando un sistema que integre la actual prestación complementaria de vivienda y las actuales deducciones fiscales por alquiler y compra.

- Las políticas de garantía de ingresos para personas con pensiones bajas, en la línea de los avances realizados en la Comunidad Foral de Navarra. Este cambio permitiría descongestionar el funcionamiento del Servicio Vasco de Empleo y mejorar la protección que hoy se da a las personas que perciben pensiones insuficientes, instaurando un sistema de deducciones anticipadas para pensionistas que integre además las actuales deducciones por dependencia y por edad, de las que no se benefician en la actualidad, plenamente al menos, los contribuyentes de menor renta.

Más complicada parece, por el contrario, la articulación de un sistema de deducciones fiscales reembolsables para trabajadores de bajos salarios, debido entre otras razones a la variabilidad de sus ingresos, al menos si se plantea como alternativa al actual sistema de estímulos al empleo integrado en la Renta de Garantía de Ingresos. Con todo, sí sería posible -manteniendo o mejorando ese modelo- rediseñar el sistema fiscal para beneficiar en mayor medida a todos los trabajadores/as de bajos salarios, independientemente de si tienen o no responsabilidades tributarias, al objeto de poner freno a la creciente desigualdad salarial y al fenómeno de la pobreza en el empleo.

Lógicamente, reformas de este tipo no podrían introducirse de la noche a la mañana de forma sistemática o generalizada. Sí cabría, sin embargo, proceder a una revisión de los sistemas de prestaciones económicas teniendo en cuenta su interacción con las actuales deducciones fiscales, de forma que se eviten las actuales lagunas y duplicidades. También sería posible avanzar de forma experimental en el desarrollo de este enfoque. En ese marco, y si existiera el consenso interinstitucional suficiente, cabría avanzar a través de: a) la elaboración de estudios de microsimulación - utilizando si fuera posible las encuestas ya disponibles en relación con la situación socioeconómica de la población vasca, así como la información tributaria que obra en poder de las Haciendas forales- que permitan evaluar ex ante los efectos y los costes de diversas alternativas y b) la extensión experimental y paulatina de estas prestaciones a algunos de los ámbitos previamente señalados.

En ese contexto, dada la relativa sencillez de la reforma y el todavía insuficiente desarrollo de las políticas vascas en materia de familia e infancia, sería factible avanzar en la legislatura que ahora se inicia hacia una mayor integración de las prestaciones por hijo/a a cargo y las deducciones fiscales por descendientes, en el marco de una renovada estrategia de apoyo a las familias con hijos/a, de impulso a la natalidad y de prevención de la pobreza infantil, tal y como el propio Plan Vasco de Apoyo a las Familias propugna. 


\section{Referencias bibliográficas}

ASTARITA, C.; MAESTRI, V. y SCHMITZ, M. L. (2016): Recent tax reforms in Italy: the impact of households and workers, Economic Brief, n-0 020, Bruselas, European Commision, 〈https://ec.europa.eu/ info/sites/info/files/file_import/ebo2o_en_2. pdf $>$.

ATHREYA, K.; REILLY, D. y SIMPSON, N. (2014): Single mothers and the earned income tax credit: insurance without disincentives?, Discussion Papers, n- 8.114, Bonn, Institute for the Study of Labor, 〈http://ftp.iza.org/dp8114.pdf〉.

AVERETT, S. y WANG, Y. (2015): The effects of the Earned Income Tax Credit on children's health, quality of home environment, and non-cognitive skills, Bonn Institute for the Study of Labor serie Discussion Papers, no 9.173, 〈http://ftp.iza. org/dp9173.pdf〉.

AVRAM, S. (2018): "Who benefits from the "hidden welfare state'? The distributional effects of personal income tax expenditure in six countries", Journal of European Social Policy, vol. 28, no 3, p. 271-293, <https://doi. org/10.1177/0958928717735061〉.

AYALA, L. y CANTÓ, O. (2009): “Políticas económicas y pobreza infantil”, en: Análisis y propuestas sobre pobreza infantil en España (Memoria de la Jornada celebrada en el Caixaforum Madrid el 13 de marzo de 2009), Madrid, Unicef Comité Español, 〈https://www.unicef.es/sites/unicef. es/files/Pobreza_Infantil_espana_unicef.pdf〉.

AYALA, L. y PANIAGUA, M. (2017): The impact of in-work benefits on female labor supply and income distribution in Spain, Euromod Working Paper, n- 17/17, Colchester, Institute for Social and Economic Research, 〈https://www.euromod. ac.uk/sites/default/files/working-papers/ em17-17.pdf〉.
AZMAT, G. y GONZÁLEZ, L. (2017): “Targeting fertility and female participation through the income tax", Labour Economics, vol. 17, no 3, shttps:// econpapers.repec.org/article/eeelabeco/ v_3a17_3ay_3a2010_3ai_3a3_3ap_3a487-502. $\mathrm{htm}>$.

BATCHELDER, L.L.; GOLDBERG, F.T. y ORSZAG, P.R. (2010): "Efficiency and tax incentives: the case for refundable tax credits", Stanford Law Review, vol. 59, no 1, p. 23-76, <http://www. stanfordlawreview.org/wp-content/uploads/ sites/3/2010/04/batchelder.pdf〉.

BITLER, M.P.; HINES, A.L. y PAGE, M. (2018): “Cash for kids”, The Russell Sage Foundation Journal of the Social Sciences, vol. 4, nํ 2, p. 43-73, 〈https:// muse.jhu.edu/article/687575/pdf>.

BREESE, H. (2018): Views on eligibility for tax credits and child benefit and any stigma associated with claiming these, Research Report, $\mathrm{n}-150$, Londres, HM Revenue and Customs, <https:// www.gov.uk/government/publications/taxcredits-and-child-benefit-customer-views-onclaimings.

BREESE, H.; MAPLETHORPE, N. y TOOMSE, M. (2011): Take-up of tax credits, Research Report, $\mathrm{n}-144$, Londres, HM Revenue and Customs, 〈https://www.gov. uk/government/publications/tax-credits-takeup-survey-and-panel-study-results〉.

CENTRE FOR SOCIAL RESEARCH AND EVALUATION (2010): Changing families' financial support and incentives for working. The summary report of the evaluation of the working for families package, Wellington, Ministry of Social Development, shttps://www.msd.govt. $\mathrm{nz} /$ documents/about-msd-and-our-work/ publications-resources/evaluation/receiptworking-for-families/wff-full-report.pdf . 
CLEGG, D. (2015): “The demise of Tax Credits", The Political Quaterly, vol. 86, nํㅜ 4.

CRANDALL-HOLLICK, M.L. y HUGHES, J.S. (2018): The Earned Income Tax Credit (EITC): An economic analysis, Washington, Congressional Research Service, 〈https://fas.org/sgp/crs/misc/R44057.pdf〉.

DAHL, G. y LOCHNER, L. (2009): "The impact of family income on child achievement: evidence from the earned income tax credit", Discussion Papers, $\mathrm{n}$ - 1.361. Madison, Institute for Research on Poverty, 〈https://www.irp.wisc. edu/publications/dps/pdfs/dp136109.pdf〉.

DE BOER, H.W.; JONGEN, E.L.W. y KABATEK, J. (2013): Comparing the effectiveness of fiscal stimuli for working parents, La Haya, CPB Netherlands Bureau for Economic Policy Analysis, <http:// conference.iza.org/conference_files/ SUMS_2013/kabatek_j8127.pdf 〉.

EAMON, M.K.; WU, C.F y ZHANG, S. (2009): "Effectiveness and limitations of the earned income tax credit for reducing child poverty in the United States", Children and Youth Services Review, vol. 31, no 8, p. 919-926.

EISSA, N. y HOYNES, H. (2008): Redistribution and tax expenditures: the earned income tax credit, Nber Working Paper, nํ⒕307, Cambridge, National Bureau of Economic Research, 〈https://www.nber.org/papers/w14307.pdf〉.

FALK, G. y CRANDALL-HOLLICK, M.L. (2014): The Earned Income Tax Credit (EITC): An overview, CRS Report, Washington, Congressional Research Service, «https://digitalcommons.ilr.cornell. edu/key_workplace/1357/>.

FAVREAULT, M.M. y JOHNSON, R.W. (2018): Distributional effects of alternative strategies for financing long-term services and supports and assisting family caregivers, CRR WP 2018-1, Chestnut Hill, Center for Retirement Research at Boston College, 〈https://crr.bc.edu/wp-content/ uploads/2018/03/wp_2018-1.pdf>.

FERRARINI, T; NELSON, K. y HÖÖG, H. (2012): “From universalism to selectivity: old wine in new bottles for child benefits in Europe and other countries", en: Minimum income protection in flux, Reconciling Work and Welfare in Europe, Nueva York, Palgrave MacMillan, pp. 137-160.

GRANTMAKERS FOR CHILDREN, YOUTH AND FAMILIES (2015): "Two generation approaches to poverty reduction and the EITC", Insight, Fall 2015, <https://eitcfunders.org/wp-content/ uploads/2015/10/GCYF-InSight-Fall-2015WEB-10-27-1.pdf .

GREGG, P.; HURRELL, A. y WITHAKER, M. (2012): Creditworthy. Assessing the impact of tax credits in the last decade and considering what this means for Universal Credit, Londres, Resolution Foundation, shttps:// www.resolutionfoundation.org/app/ uploads/2014/08/Creditworthy.pdf〉.

GULDI, M. y SCHMIDT, L. (2017): “Taxes, transfers, and women's labor supply in the United States", en The Oxford Handbook of Women and the Economy, Nueva York, Oxford University Press, 〈https://www.itd.bus.ucf.edu/cdn/economics/ workingpapers/2017-01.pdf〉.
HAMAD, R. y REHKOPF, D.H. (2016): "Poverty and child development: A longitudinal study of the impact of the Earned Income Tax Credit", American Journal of Epidemiology, vol. 183, $\mathrm{n}$ 9, p. 775-784, 〈https://doi.org/10.1093/aje/ kwV317>.

HERMIDA, P. y NOGUERA, J.A. (2016): “Integración de impuestos y prestaciones: una vía innovadora para la reforma de la protección social", Documentación Social, no 169, págs. 105-126.

HM REVENUE \& CUSTOMS (2012): Child benefit, child tax credit and working tax credit, Take-up rates 2010-11, Londres, HM Revenue \& Customs, <https://webarchive.nationalarchives.gov. uk/20140108151505/http://www.hmrc.gov.uk/ statistics/fin-takeup-stats/cwtc-take-up.pdf>.

HOLT, S. (2011): Ten years of the EITC movement: making work pay then and now, Washington, Brookings, shttps://www.brookings.edu/ research/ten-years-of-the-eitc-movementmaking-work-pay-then-and-now/>.

HOYNES, H. (2017): The Earned Income Tax Credit: A key policy to support families facing wage stagnation, Berkeley, Institute for Research on Labor and Employment, 〈http://irle.berkeley. edu/files/2017/IRLE-The-Earned-Income-TaxCredit.pdf〉.

HOYNES, H.W.; MILLER, D. y SIMON, D. (2015): "Income, the earned income tax credit, and infant health", American Economic Journal: Economic Policy, vol. 7, n- 1, p. 172-211, 〈https://doi.org/10.1257/ pol.20120179'.

- (2012): Income, the earned income tax credit, and infant health, Nber Working Paper, $\mathrm{n}$-18.206. Cambridge, National Bureau of Economic Research, «https://www.nber.org/papers/ w18206.pdf>.

- (2012): The EITC: Linking income to real health outcomes, Policy Brief, Davis, Center for Poverty Research, 〈http://poverty.ucdavis.edu/sites/main/files/ file-attachments/policy_brief_hoyes_eitc_o. pdf〉.

JOHNSON, P. (2012): “Fairer by design: efficient tax reform for those on low to middle incomes", Londres, Resolution Foundation, <https:// www.resolutionfoundation.org/publications/ fairer-design-efficient-tax-reform-low-middleincomes/>.

JONES, L.E.; MILLIGAN, K.S. y STABILE, M. (2015): Child cash benefits and family expenditures: evidence from The National Child Benefit, NBER Working Paper, $\mathrm{n}$ - 21.101, Cambridge, National Bureau of Economic Research, 〈https://www.nber.org/ papers/w21101.pdf〉.

JONES, M.R. y ZILIAK, J.P. (2019): The antipoverty impact of the EITC: new estimates from survey and administrative tax records, CES Research Papers, n- 19-14, <https://www2.census.gov/ ces/wp/2019/CES-WP-19-14.pdf .

LEIGH, A. (2010): Who benefits from the earned income tax credit? Incidence among recipients, coworkers and firms, IZA Discussion Papers, $\mathrm{n}$ - 4.960, Bonn, Institute for the Study of Labor, <http:// ftp.iza.org/dp4960.pdf〉.

LEVY, H.; MATSAGANIS, M. y SUTHERLAN, H. (2013): Towards a European Union Child Basic Income? Within 
and Between Country Effects, EUROMOD Working Paper, EM 6/13, <https://www.iser. essex.ac.uk/publications/working-papers/ euromod/em6-13.pdf>.

MANOLI, D. y TURNER, N. (2018): “Cash-on-hand and college enrollment: evidence from population tax data and the earned income tax credit", American Economic Journal: Economici Policy, vol. 10, nํㅜ 2, p. 242-271, 〈https://doi.org/10.1257/ pol.20160298>.

MARR, C.; CHARITE, J. y HUANG, C.C. (2013): Earned income tax credit promotes work, encourages children's success at school, research finds. For children, research indicates that work, income, and health benefits extend into adulthood, Washington, Center on Budget and Policy Priorities, <https://www.siis.net/es/ documentacion/catalogo/Record/192025>.

MARR, C. et al. (2015): EITC and Child Tax Credit promote work, reduce poverty, and support children's development, research finds, Washington, Center on Budget and Policy Priorities, <https:// www.cbpp.org/sites/default/files/atoms/ files/6-26-12tax.pdf>.

MCCABE, J.T. (2018): The Fiscalization of social policy. How Taxpayers trumped children in the fight against child poverty, Nueva York, Oxford University Press.

MCCABE, J.T. y POPP, E. (2016): “American exceptionalism revisited: tax relief, poverty reduction, and the politics of child tax credits", Sociological Science, vol. 3, p. 540-567, <https://doi. org/10.15195/v3.a24>.

MCGRANAHAN, L. (2016): Tax credits and the debt position of US households, Chicago, Federal Reserve Bank of Chicago, Working Paper 2016-12. <https:// www.chicagofed.org/ /media/publications/ working-papers/2016/wp2016-12-pdf.pdf〉.

MENDELHALL, R. et al. (2012): "The role of earned income tax credit in the budgets of low-income households", Social Service Review, vol. 86, no 3 , p. 367-400.

MEYER, B.D. (2010): "The effects of the earned income tax credit and recent reforms", Tax Policy and the Economy, vol. 24, nํㅜ 1, p. 153-180, <https://doi. org/10.1086/649831).

MILLAR, J. (2008): “Lograr que el trabajo reditúe y que los créditos impositivos funcionen: una evaluación haciendo referencia específicamente al empleo de padres y madres solos al frente del hogar", Revista Internacional de Seguridad Social, vol. $61, \mathrm{n}-2$, p. 23-43.

MIRRLEES, J. et al. (2008): Integrating personal taxes and benefits, Mirrlees Review, $\mathrm{n}-5$, Londres, Institute for Fiscal Studies, <https://www.ifs. org.uk/mirrleesreview/design/ch5.pdf〉.

MOFFITT, R.A. (2003): The negative income tax and the evolution of U.S. welfare policy, NBER Working Paper, no 9.751, Cambridge, National Bureau of Economic Research, 〈https://www.nber.org/ papers/w9751.pdf $\rangle$.

- (2004): The idea of a negative income tax: past, present, and future. Focus, Discussion Papers, vol. 23, n. 2, p. 1-8, <https://www.ssc.wisc.edu/

irpweb/publications/focus/pdfs/foc232a.pdf $\rangle$.

NICHOLS, A. y ROTHSTEIN, J. (2015): The Earned Income Tax Credit (EITC), NBER Working Paper, n을.211, Cambridge (MA), National Bureau of Economic Research, <https://www.nber.org/papers/ w21211.pdf〉.

NOGUERA, J. A. (2016): “El Estado de bienestar oculto en España”, Agenda Pública, 12 de septiembre, 〈http://agendapublica.elpais.com/el-estadode-bienestar-oculto-en-espana/ .

ROTHSTEIN, J. (2009): Is the EITC equivalent to an NIT? Conditional cash transfers and tax incidence, Nber Working Paper, no 14.966, Cambridge, National Bureau of Economic Research, 〈https://www.nber.org/papers/w14966.pdf〉.

ROTHSTEIN, J.; PRINCETON UNIVERSITY y NBER (2008): The unintended consequences of encouraging work: tax incidence and the EITC, Working Paper, $n \div$ 165, Princeton, Princeton University, 〈http://www.princeton.edu/gceps/ workingpapers/165rothstein.pdf>.

SANZO, L. y PINILLA, R. (2004): La renta básica. Para una reforma del sistema fiscal y de protección social, Documentos de Trabajo, nํㅜ 42. Madrid, Fundación Alternativas, <https:// www.fundacionalternativas.org/laboratorio/ documentos/documentos-de-trabajo/la-rentabasica-para-una-reforma-del-sistema-fiscal-yde-proteccion-social>.

SIIS CENTRO DE DOCUMENTACIÓN Y ESTUDIOS (1999): Políticas de "Welfare to Work" en Estados Unidos, Donostia-San Sebastián, SIIS Centro de Documentación y Estudios, 〈https://www.siis. net/es/investigacion/ver-estudio/437/>.

SIMPSON, N.B.; TIEFENTHALER, J. y HYDE, J. (2010): “The impact of the earned income tax credit on economic well-being: a comparison across household types", Population Research and Policy Review, vol. 29, nㅇ 6, p. 843-864.

SIMPSON, W. y STEVENS, H. (2016): The Disability Tax Credit: why it fails and how to fix it, SPP Research Papers, vol. 9, nํㅜㄴ 24, p. 1-23, <https://www. policyschool.ca/wp-content/uploads/2016/07/ disability-tax-credits-simpson-stevens.pdf〉.

TONDANI, D. (2009): “Universal basic income and negative income tax: two different ways of thinking redistribution", The Journal of Socio-Economics, vol. $38, n^{0} 2$, p. 246-255.

VERBIST, G.; DE LATHOUWER, L. y ROGGEMAN, A. (2005): Labour market activation policies. A comparison of the use of tax credits in Belgium, the UK and the US, Amsterdam, Managing Social Risks Through Transitional Labour Markets, 〈https:// core.ac.uk/display/55805930>.

ZALAKAIN, J. (2006): “Trabajo, trabajadores pobres e inserción social”, Documentación Social, noㅡ 143, págs. 45-76.

- (2014): “El papel de los sistemas de garantía de ingresos en el abordaje de la pobreza en el empleo: la experiencia del País Vasco", Lan Harremanak, no 31, págs. 36-62, 〈http://www.ehu.eus/ ojs/index.php/Lan_Harremanak/article/ view/15167/o>. 